\title{
Carbon Nanotubes and Carbon Nanotubes/Metal Oxide Heterostructures: Synthesis, Characterization and Electrochemical Property
}

\author{
Yong $\mathrm{Hu}$ and Changfa Guo \\ Zhejiang Key Laboratory for Reactive Chemistry on Solid Surfaces and Institute of \\ Physical Chemistry, Zhejiang Normal University, Jinhua,
}

China

\section{Introduction}

Carbon nanotubes (CNTs), a novel carbonaceous material, have been widely studied since their discovery in 1991. CNTs have highly unique electronic, mechanical, catalytic, adsorption, and transport properties, making them interesting for a variety of applications. It is very important for the use of CNTs to prepare CNTs with various constructs in large scale and ideal quality. Up to now, CNTs have been produced by various kinds of strategies, mainly including Arc discharge, laser ablation, and chemical vapor deposition (CVD). Compared with the other two methods, CVD is considered as the most promising method for easily scaled-up to batch-scale production duo to simplicity and economy. At present, a lot of modified CVD were studied and explored for preparing pure CNTs in large scale, especially single-walled CNTs (SWCNTs), such as plasma-enhanced CVD (PECVD) and thermal CVD. A vapor-liquid-solid (VLS) mechanism is generally accepted for CNTs growth, and catalyst plays an important role in the CVD synthesis of CNTs, which is needed to be removed in follow purity of CNTs for further use. To avoid the problem, some modified CVD methods without metal particles as catalyst were also carried out for producing relative pure CNTs.

CNTs possess large specific surface areas due to their high aspect ratio, while their structural integrity and chemical inertness support relatively high oxidation stability in comparison with graphite. For these reasons, CNTs are promising building blocks for hybrid materials, which could endow CNTs more excellent performances for widely potential fields. CNTs-based hybrid materials, including CNTs-inorganic species and CNTsorganic species, were synthesized by numerous diverse strategies, which can be classed roughly into two kinds: ex situ approach (attaching nanoparticles to CNTs) and in situ synthesis (Directly on the CNTs surface). CNTs/metal oxide heterostructures are an important kind of CNTs-inorganic composites. The synergistic effect of CNTs and metal oxide makes CNTs/metal oxide heterostructures possess the properties of the both and have more widely potential application. The electrochemical properties of the CNTs/metal oxide heterostructures have attracted researchers' interest duo to their excellent 
performances on electrochemical catalyst, electrochemical sensor, supercapacitors and batteries. Over the past few years a great number of CNTs/metal oxide heterostructures, such as $\mathrm{TiO}_{2} / \mathrm{CNTs}, \mathrm{Co}_{3} \mathrm{O}_{4} / \mathrm{CNTs}$, $\mathrm{Au} / \mathrm{CNTs}, \mathrm{Au} / \mathrm{TiO}_{2} / \mathrm{CNTs}, \mathrm{Co} / \mathrm{CoO} / \mathrm{Co}_{3} \mathrm{O}_{4} / \mathrm{CNTs}$ (Fig. i) [1] etc, were synthesized and their electrochemical properties were investigated as well.

Numerous synthetic methodologies have been developed for the preparation of CNTs and their composites. In this chapter, besides the preparation of nanocomposites based on CNTs, we also focus on investigating the electrochemical applications of $\mathrm{CNT} /$ metal-oxide or hydroxide composites.
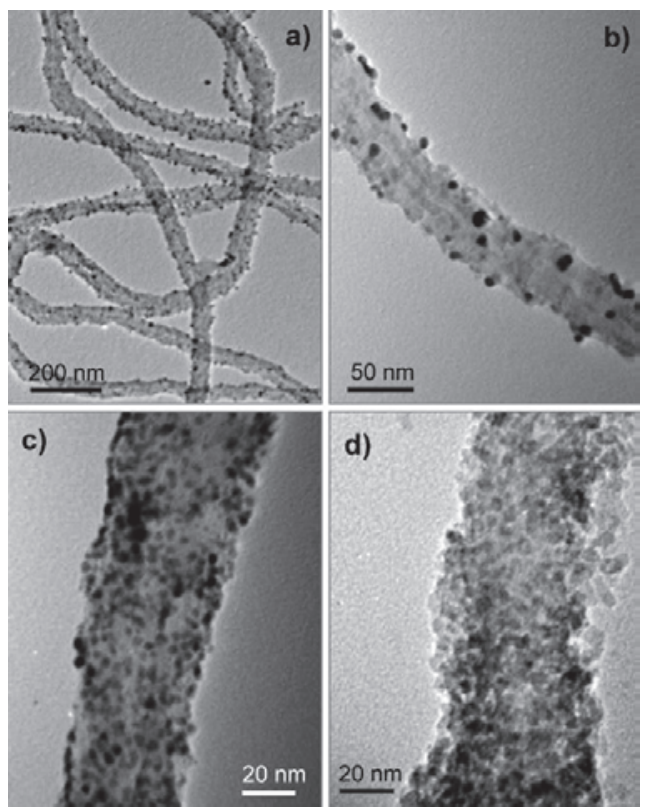

Fig. i. a) and b) a large view and a detailed view on the $\mathrm{Au} / \mathrm{TiO}_{2} / \mathrm{CNT}$ nanocomposites prepared by the photo-assisted method, (c) a detailed view on the $\mathrm{Au} / \mathrm{TiO}_{2} / \mathrm{CNTs}$ prepared by the self-assembly method, and (d) a detailed view on the $\mathrm{TiO}_{2} / \mathrm{Co}_{3} \mathrm{O}_{4} / \mathrm{CNTs}$ nanocomposite prepared by the self-assembly method. (Courtesy of J. Li et al. [1])

\section{Synthesis of CNTs}

CNTs with tubular structures are made entirely of rolled-up layers of interconnected carbon atoms [2,3], and with diameters ranging from about one nanometer to tens of nanometers and lengths up to centimeters. CNTs can be open-ended or closed by a hemispherical fullerene-type cap, depending on their synthesis method [4]. CNTs have highly unique electronic, mechanical, catalytic, adsorption, and transport properties, making them interesting for a variety of applications [5-13]. The scale-up preparation of CNTs with high purity and homogeneity is essential for the use of CNTs in reality. In several past decades, a lot of effort was made to investigate the synthesis strategies of CNTs and modify constantly the promising methods. By far, various strategies, maily including Arc discharge, laser 
ablation, and various chemical vapor depositions (CVD), have been found to produce SWCNTs and MWCNTs with different merit and demerit. In this section, a brief discussion about the progress in preparation of CNTs is divided into two parts (synthesis of SWCNTs and synthesis of MWCNTs) and made.

\subsection{Synthesis of SWCNTs}

SWCNT can be considered to be a unique molecule, with different physical properties, depending on their chirality, which determines that SWCNTs are primarily metallic or semiconducting. Although obtaining a single aliquot of one $(n, m)$ nanotube is not necessary in some cases, it is still necessary to obtain nanotubes that are free of non-nanotube carbon impurities and metal catalyst particles (employed to make SWCNTs).

SWCNTs were first synthesized by the coevaporation of a cobalt catalyst and graphite in an electric arc $[3,14]$. In the early arc-generated nanotube material, the SWCNT fibers typically consisted of 7-14 bundled SWCNTs, with the individual tubes being 1.0-1.5 nm in diameter. The early arc-generated materials also contained relatively low weight percent densities of SWCNTs. An improvement in the nanotube yield was observed by changing the metal catalysts employed in the arc-technique [15]. Fig. 1a displays a transmission electron microscope (TEM) image of a typical arc SWCNT material generated with an iron catalyst [16]. Note that the nanotube bundles are relatively small (containing 3-5 nanotubes). SWCNTs were later produced at much higher yield by the method of laser vaporization [17]. Crystalline ropes micrometers in length containing 10-100 s of individual SWCNTs were easily obtained [18]. Fig. 1b shows a typical TEM image of crude laser-generated material produced with an Alexandrite laser operating at $\sim 45 \mathrm{~W} / \mathrm{cm}^{2}$, with Co and $\mathrm{Ni}$ at $0.6 \%$ each and an external furnace temperature of $1200{ }^{\circ} \mathrm{C}$ [19]. Note the large, very long bundles of SWCNTs present in Fig. 1b. Although there is a high density of SWCNTs (30-40 wt \%), non-nanotube carbon impurities, as well as metal catalyst particles, are still clearly visible in the TEM image. Laser-generated SWCNTs typically have low defect concentrations [20], making them easier to purify, since they are not as likely to be destroyed by the acids generally employed to remove metal catalyst particles. For example, Laser-genrated SWCNTs were purified with dilute $\mathrm{HNO}_{3}$ to remove the metal catalyst particles and then burned in air at $550{ }^{\circ} \mathrm{C}$ to remove the non-nanotube carbon [21]. However, the laser technique is often considered to be too expensive to be industrially scalable.

Consequently, numerous research groups have turned to the development of CVD as a potentially low-cost scalable technique for the production of SWCNTs. In 1996, SWCNT growth employing CVD on a supported catalyst was demonstrated as a promising route to carbon nanotube production [22]. Multiple reports quickly followed, further establishing CVD as a viable large-scale production process [23-32]. Typically, CVD materials contain more metal and often smaller and shorter SWCNT bundles than those produced in the laser processes. Fig. 1c shows a TEM image of commercially available CVD material produced by a high pressure carbon monoxide (HiPCO) process [29]. CVD production of isolated nanotubes has been achieved on oxidized silicon substrates using an iron catalyst [33]. Additionally, isolated SWCNTs have been generated in the gas phase by the technique of hot wire chemical vapor deposition (HWCVD) [34]. Fig. 1d shows high-resolution TEM images of isolated SWCNTs produced by this HWCVD process. For comparison, a high resolution TEM image of a bundle of purified laser-generated SWCNTs is also provided in 
Fig. 1e [9]. A multistep process for the purification of HiPCO CVD-generated nanotubes was reported in 2001 [35]. Recently, K. E. Hurst reported a simple "laser cleaning" method than can be employed to purify a host of CNT materials [36]. The unavoidable metal species remaining in the SWCNT products would result in obvious disadvantages for both intrinsic property characterization and application exploration of SWCNTs. Despite sustained efforts, it has been until now an intractable problem to remove metal catalysts completely from SWCNT samples without introducing defects and contaminations. Surprisingly, in 2009, Liu et al. proposed a simple and effective method for growing SWCNTs via a metal-catalyst-free CVD process on a sputtering deposited $\mathrm{SiO}_{2}$ film. Metal-free, pure, and dense SWCNTs were obtained [37]. The successful growth of SWCNTs using a nonmetal catalyst can provide valuable implications for understanding the growth mechanism of SWCNTs indepth, which accordingly will facilitate the controllable synthesis and applications of carbon nanotubes.
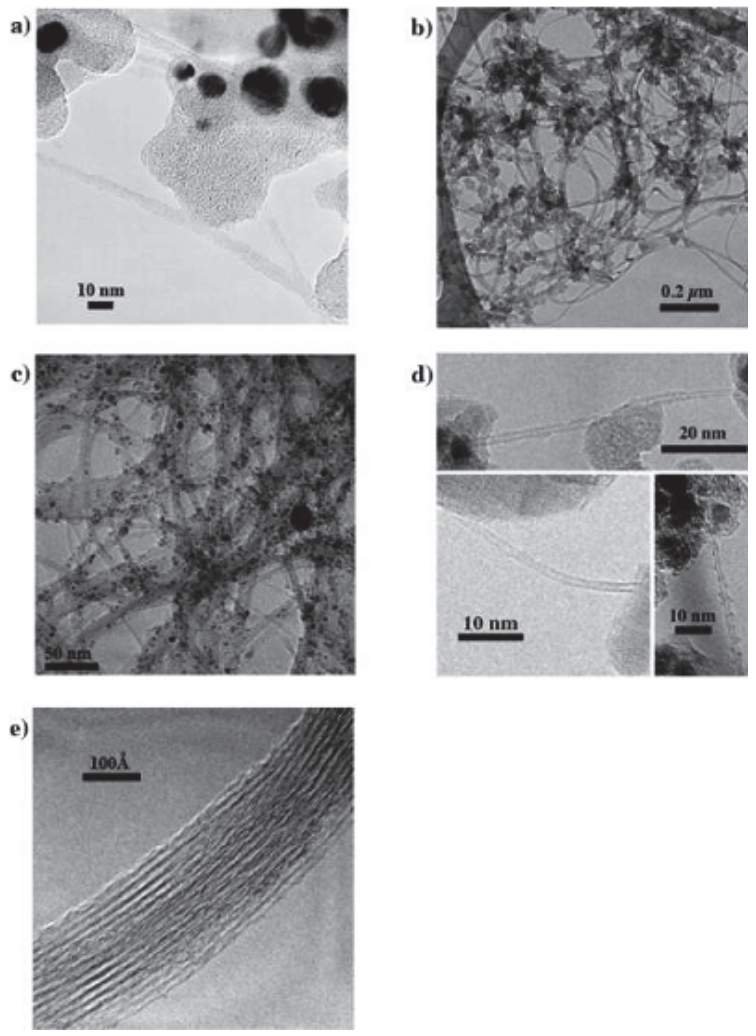

Fig. 1. TEM images of bulk SWCNT materials showing (a) typical arc-material generated with a $\mathrm{Co} / \mathrm{Ni}$ catalyst mixture. (b) Alexandrite laser-generated crude material produced with $\sim 45 \mathrm{~W} / \mathrm{cm}^{2}$ and a Co/ Ni catalyst mixture at $1200^{\circ} \mathrm{C}$. (c) commercially available CVD material produced by the HiPCO process. (d) Isolated SWCNTs produced by a continuous HWCVD process where ferrocene is employed to supply the metal catalyst. (e) Bundle of purified laser-generated SWCNTs. (Courtesy of A. C. Dillon et al. [5]) 


\subsection{Synthesis of MWCNTs}

MWCNTs were discovered by Iijima in 1991 while vaporizing carbon in an electric arc [2] and were then produced at higher yield by increasing the pressure of the helium gas atmosphere [38]. MWCNTs typically have inner diameters of $\sim 3-20 \mathrm{~nm}$ and are then surrounded by concentric graphene sheets with an interstitial spacing between the sheets of $\sim 3.4 \AA$. The number of concentric graphene sheets can range from 2 to $\sim 100$. High resolution TEM images of MWCNTs are provided in Fig. 2 [39]. In Fig. 2a the high-resolution TEM image clearly shows that the distance between layers of the MWCNTs measures $\sim 3.4 \AA$. Fig. $2 \mathrm{~b}$ depicts a MWCNT with $\sim 20$ concentric shells. MWCNTs have electronic properties similar to those of graphite and are thus semimetals. They are promising for multiple applications including strong composite materials, field emission displays, and adsorbents for gas separation or storage [40-47].

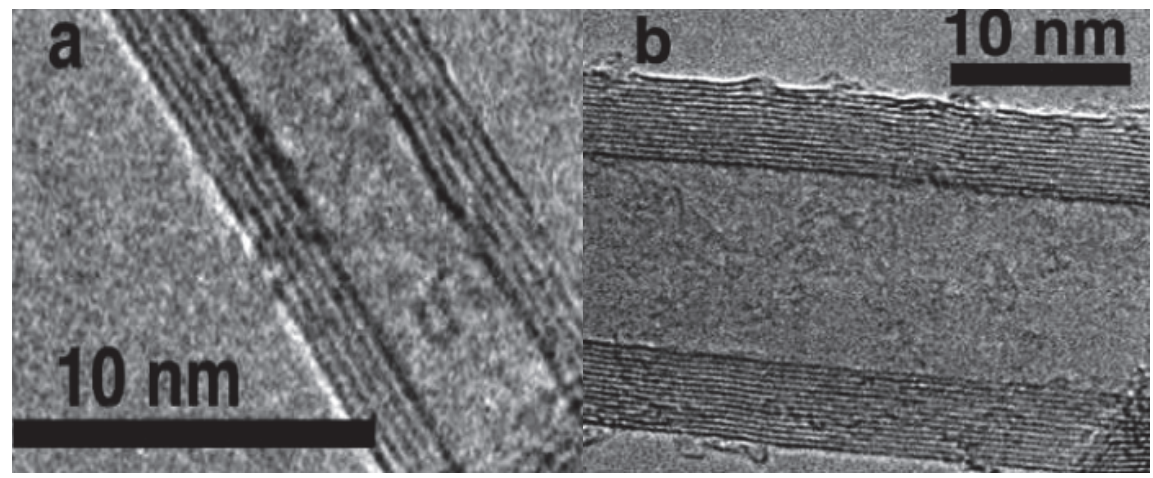

Fig. 2. TEM images of MWCNTs (a) showing that the distance between layers of the MWCNTs measures $\sim 0.34 \mathrm{~nm}$ and (b) depicting a MWCNT with $\sim 15$ concentric shells. (Courtesy of A. C. Dillon et al. [39])

Similar to SWCNTs, a continuous low-cost production method producing MWCNTs that are easily purified is required for MWCNTs to be incorporated in emerging technologies. In 1997 [48] and 1998 [49], ferrocene was utilized as a gas-phase catalyst in a CVD process for continuous MWCNT formation from methane at $1150{ }^{\circ} \mathrm{C}$. However, the 1997 study reported materials containing more amorphous carbon than arc-generated MWCNTs, presumably due to a lower synthesis temperature than that achieved in the arc process [48]. In the 1998 study, the outer layers of the tubes were not graphitic [49], making them more difficult to purify. Later, ferrocene and ethylene were employed in CVD of MWCNTs between 650 and $950{ }^{\circ} \mathrm{C}$ [50]. Again, carbon impurities were observed at high-density. The authors concluded that further work was necessary to improve the nanotube microstructure and yield [50]. Highpurity aligned, graphitic MWCNTs were synthesized via decomposition of a ferrocene-xylene mixture at $\sim 675^{\circ} \mathrm{C}$. However, although the catalyst was supplied in the gas-phase, nucleation of tube growth occurred only for iron species deposited on a quartz substrate, resulting in a surface growth mechanism and limiting yields to available surface area [51]. CVD techniques employing benzene pyrolosis [52] and the decomposition of ethylene [53] and acetylene [54] on supported metal catalysts have been demonstrated as viable large-scale production methods. MWCNTs have also been grown on supported metal particles or films via CVD [5559], plasma-enhanced CVD [60-70], hot-wire chemical vapor deposition [71,72], and plasma- 
enhanced HWCVD methods [73,74]. One HWCVD report employed evaporation of the Fe-Cr filament to supply a gas-phase catalyst, resulting in MWCNTs with a high density of structural defects and significant carbon impurities [75]. Although more research was deemed necessary, this method had potential for large-scale production, since it was not substrate dependent. In 2003, the first continuous high-density MWCNT formation with minimal non-nanotube carbon impurites was demonstrated with HWCVD employing methane as the carbon source and ferrocene as a gas-phase catalyst [39]. The metal catalyst impurities were simply removed via refluxing in dilute $\mathrm{HNO}_{3}$ [39]. Surprisingly, Multi-walled carbon nanotubes has been synthesized using acetylene as carbon sources with a metal-free mild chemical vapor deposition process by $\mathrm{Du}$ et al. [76]. The authors not only gave a simple and facile way to synthesize MWCNTs without metal but also provided valuable information for a deeper understanding of CNT formation in CVD.

\section{Synthesis of CNTs/metal oxide heterostructures}

The transition metal oxides are an important family of inorganic nanomaterials with abundant properties in optics, electronics, magnetics and catalysis. The property of metal oxide nanomaterials can be further tuned by varying their composition, structure and morphology [77].

Composite materials based on CNTs and metal oxide nanomaterials integrate the unique characters and functions of the two types of components and may also exhibit some new properties caused by the cooperative effects between the two kinds of materials [78-82]. Therefore, these composite materials have shown very attractive potential applications in many fields. This section summarizes the handling of CNTs and the preparation of CNTbased nanocomposites.

\subsection{Purification and dispersion of CNTs}

Generally, the carbon nanotubes as-prepared are grown as mixtures of carbon nanotubes and impurities such as amorphous carbon, metal catalyst particles and carbon nanoparticles. These impurities significantly influence the properties of CNTs and limit their applications. Consequently, development of economical purification methods has become an important issue to the development and practical applications of the CNTs. A commonly used purification approach consists of two steps. The thermal or acid oxidation treatment on raw CNTs can effectively remove the amorphous carbon, carbon nanoparticles and carbon layers coated on the metal particles [83,84]. The following acid refluxing treatment removes the residual naked metal-oxide particles [85]. This method is time consuming and has the disadvantage of low yield and damaging the nanotubes. Some extraordinary methods such as magnetic filtration, microwave irradiation, electrochemical oxidation, surfactant-assisted purification and $\mathrm{C}_{2} \mathrm{H}_{2} \mathrm{~F}_{4}$ or $\mathrm{SF}_{6}$ treatment have shown higher efficiency in removing the contaminants in the CNT samples and are less damaging to the nanotube structure [86-89].

Due to the strong $\pi-\pi$ stacking interactions between the neighboring CNTs, they tend to aggregate into bundles, making it very difficult for them to be dispersed in water and organic solvents. Their insolubility has become a great obstacle to the manipulation and application of CNTs. Dispersing nanotubes at the individual nanotube level is critical for a better performance of CNTs in most applications, especially the preparation of CNT-based composites. Therefore, many strategies have been explored to improve the solubility of CNTs in solvents. They can be classified mainly into two types, one is the sidewall covalent 
functionalization, and the other is the noncovalent modification using guest molecules as solubilizers. By sonication in mixtures of sulfuric and nitric acids or sulfuric acid and hydrogen peroxide, carbonyl and carboxylic groups can be introduced onto the nanotubes [90]. This is one of the most prevalently used covalent modification methods. The modified CNTs can be further functionalized by esterification or amidation reaction [91,92]. Other methods such as carbene cycloaddition, diazonium reaction and grafting of polymers have also been successfully used in the functionalization of CNTs [93,94]. The covalent methods convert the carbon atom hybridization from $\mathrm{sp}^{2}$ to $\mathrm{sp}^{3}$, leading to a disruption of electronic structure of CNTs. The noncovalent modification methods, such as polymer and DNA wrapping, $\pi-\pi$ stacking interactions with aromatic molecules and surfactant-assisted dispersion, are based on van der Waals or $\pi$ - $\pi$ stacking between CNTs and solubilizer molecules [95-98]. The noncovalent strategy offers the advantage of remarkably improving the CNTs' solubility without disrupting the electronic structure of the tubes. Therefore it is more attractive than the covalent method for the maintenance of pristine structure and properties of CNTs. SWCNTs can be directly dispersed in the imidazolium-based ionic liquids simply by mechanical milling. The concentration of SWCNTs can be as high as $1 \mathrm{wt} \%$, which is remarkably higher than that of conventional covalent and noncovalent approaches [99]. The prosperities of SWCNTs are well preserved, since only weak van der Waals force exists between SWCNTs and ionic liquids [100,101]. Therefore, imidazoliumbased ionic liquids are superior solvents for the handling of CNTs [100,101].

\subsection{Filling CNTs}

The earliest attempt toward CNT-inorganic hybrids (in 1993) was the filling of MWCNTs with metal oxides (PbO [102] and $\mathrm{Bi}_{2} \mathrm{O}_{5}$ [103]). Because of their larger inner diameter (5-50 nm) compared with SWCNTs (1-1.5 nm), most efforts had been spent on filling MWCNTs, and it was not until five years later that Sloan et al. reported the filling of SWCNTs with $\mathrm{RuCl}_{3}$ [104]. Recently, a few of researchers reported that magnetic nanoparticles or nanowires, such as cobalt, iorn and corresponding oxides, filled carbon nanotubes by various technologies and their properties were investigated as well [105-107]. However, carbon nanotube is difficult to be filled fully without few impurities duo to capillarity of itself.

Initially, the motivation arose mainly from the prospect of forming encapsulated or (upon oxidation) freestanding inorganic nanowires with new crystal structures or novel properties. Although both MWCNTs and SWCNTs have been filled with a vast number of compounds, little is known about their properties and potential in applications. This has been frequently blamed on high impurity levels in the synthesized hybrids, the lack of bulk quantities, and the need for specifically designed measurement devices [108]. In general, the distinction should be made between the intrinsic properties of the filler, the altered properties of the encapsulated material due to the confined-space, and novel properties arising from interactions between the filler and CNTs.

\subsection{Ex situ approach: attaching metal oxide nanoparticles to CNTs}

In this ex situ or building block approach, metal oxide nanoparticles are attached to the CNTs via linking agents that utilize covalent, п-п Stacking, or electrostatic interactions. In this approach, either the metal oxide nanoparticles or the CNTs (or the both) require modification with functional groups. The type of functionalization and, thus, the strength of interaction determine the distribution and concentration of the metal oxide nanoparticles on the CNT surface. 


\subsubsection{Covalent Interactions}

Carboxyl groups on the surface of acid-treated CNTs are often used to attach amineterminated or mercapto-terminated metal oxide nanoparticles via amide bonds [109]. This can be achieved either by directly linking amine-terminated or mercapto-terminated nanoparticles with the carboxyl groups or by modifying these carboxyl groups into thiol groups, which then anchor to colloidal nanoparticles. In a similar way, QDs have been linked by first stabilizing them with a mixed monolayer of trioctylphosphine oxide (TOPO) and 2-aminoethanethiol [110]. The resulting amino-functionalized QDs then reacted with the carboxylic groups of the acid-treated CNTs to form amide bonds.

Metal oxides can be attached to the carboxyl groups without any linking agent due to their hydrophilic nature, as recently demonstrated for $\mathrm{MnO}_{2}$ [111], $\mathrm{MgO}$ [112], and $\mathrm{TiO}_{2}$ [113]. However, the authors observed only weak interactions between the oxides and the acidterminated CNTs, resulting in rather nonuniform distributions of the nanoparticles. Better adhesion was observed when capping agents were used. For instance, Sainsbury and Fitzmaurice produced capped $\mathrm{TiO}_{2}$ via a standard sol-gel process using titanium tetraisopropoxide (TTIP) as precursors with cetyltrimethyl ammoniumbromide (CTAB) as the capping agent [114]. MWCNTs were modified with 2-amino-ethylphosphoric acid and then mixed with the oxide nanoparticles. The authors showed that the phosphonic acid groups on the CNTs were well-distributed and provided an excellent driving force for the attachment of $\mathrm{TiO}_{2}$ nanoparticles (Fig. 3).

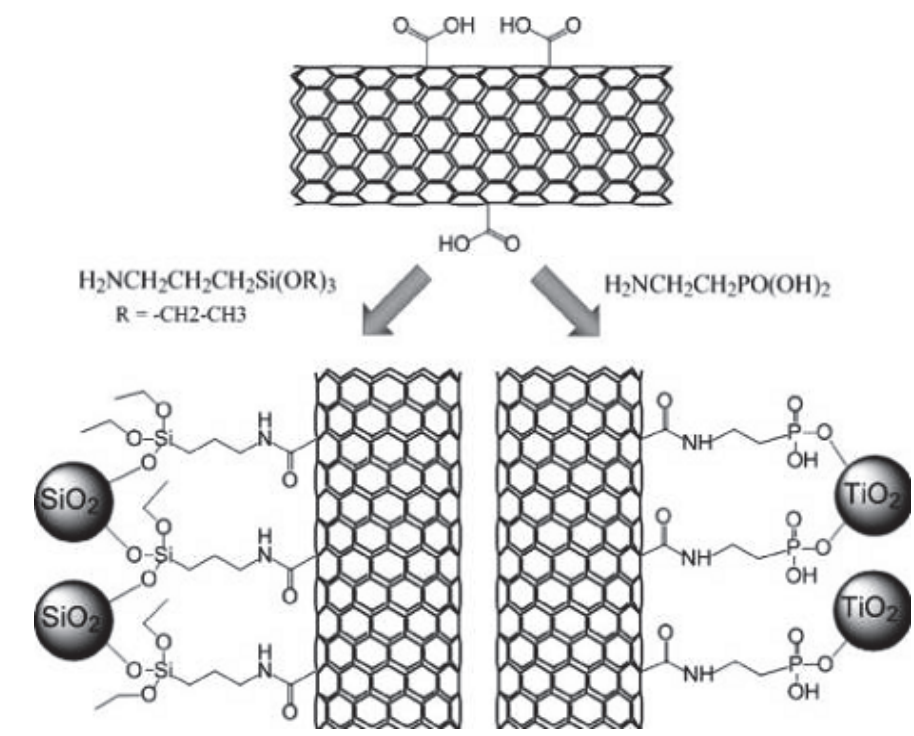

Fig. 3. Example of an ex situ attachment of $\mathrm{SiO}_{2}$ and $\mathrm{TiO}_{2}$ nanoparticles to functionalized CNTs via silane and phosphonic acid bonds, respectively. (Courtesy of T. Sainsbury et al. [114])

\subsection{2 $\pi-\pi$ stacking}

This approach uses the moderately strong interactions between delocalized $\Pi$-electrons of CNTs and those in aromatic organic compounds, such as derivatives of pyrene [115-117], porphyrins [118-120], phthalocyanines [121], or combinations thereof [122], as well as benzyl 
alcohol or triphenylphosphine (Fig. 4) [123]. These molecules are often modified with long alkyl chains that are terminated with thiol, amine, or acid groups, which can then connect to metal oxide nanoparticles and enable their attachment to pristine CNTs via п-п stacking. For example, Li et al. used pyrene derivatives with a carboxylic termination to anchor magnetic nanoparticles such as $\mathrm{Co}$ or $\mathrm{Fe}_{3} \mathrm{O}_{4}$ [124].

One of the major advantages of this approach is that the pyrene compounds remain strongly adsorbed on the CNT surface after workup steps (e.g., washing, filtration) and thus provide enhanced solubility and allow continuous redispersing of the modified CNTs in various aqueous and organic solvents. Furthermore, spectroscopic experiments on CNT/Pt [125] and CNT/porphyrin hybrids $[118,126]$ revealed an enhanced charge transfer from inorganic nanoparticles to the CNTs, mediated by the aromatic compound. This was also observed for attached $\mathrm{Co}$ and $\mathrm{Fe}_{3} \mathrm{O}_{4}$ nanoparticles [124], whose magnetic and electronic properties were altered due to a strong electron transfer. Moreover, this effect is tunable by the length of the chain.

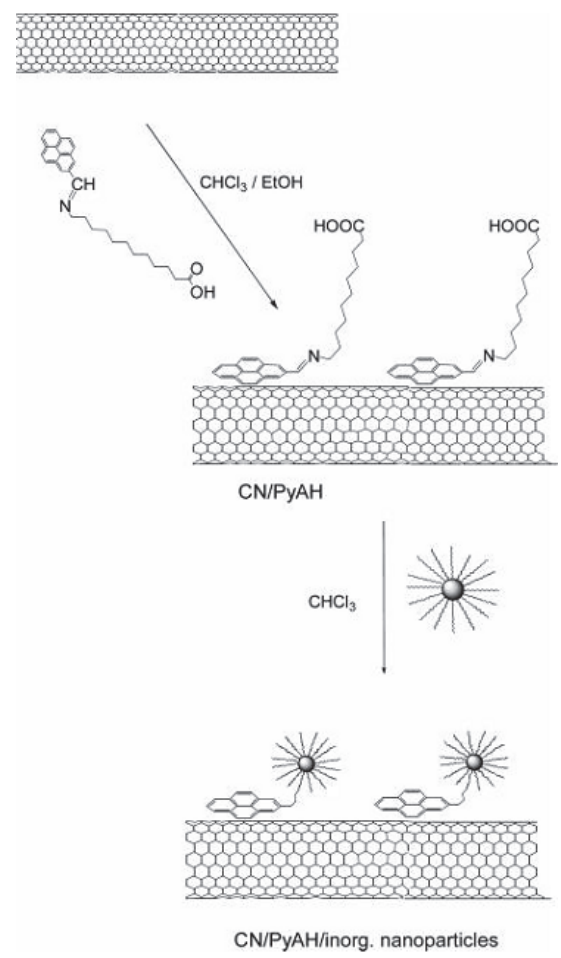

Fig. 4. Examples of linking agents and ligands used to attach metal (oxide) nanoparticles to pristine CNTs via п-п interactions: pyrene derivatives. (Courtesy of V. Georgakilas et al. [124])

\subsubsection{Electrostatic interactions}

The approach utilizes electrostatic interactions between modified CNTs and metal oxide nanoparticles. Among the known examples, the deposition of ionic polyelectrolytes to attract charged nanoparticles is the most common route [127-131]. These polyelectrolytes 
typically bond covalently to the functional groups on the CNT, in contrast to polyethyleneimine (PEI), which interacts with CNTs via physisorption [132]. For instance, Sun et al. deposited $\mathrm{Al}_{2} \mathrm{O}_{3}, \mathrm{ZrO}_{2}$, and $\mathrm{TiO}_{2}$ nanoparticles on charged CNTs in a slightly modified way [133]. CNTs were pretreated in $\mathrm{NH}_{3}$ at $600{ }^{\circ} \mathrm{C}$ to induce a positive surface charge. The addition of PEI increased the positive charges even further and enabled a better dispersion. Commercially available $\alpha-\mathrm{Al}_{2} \mathrm{O}_{3}$ and $3 \mathrm{Y}-\mathrm{TZP}$ were then dispersed in poly(acrylic acid) (PAA), which provided a negative surface potential over a wide range of $\mathrm{pH}$ values. Upon mixing, the $\mathrm{Al}_{2} \mathrm{O}_{3}$ and $\mathrm{ZrO}_{2}$ nanoparticles formed strong electrostatic attractive interactions and covered the CNT surface completely.

Sun et al. attached nanocrystals of $\mathrm{TiO}_{2}$ to acid-treated SWCNTs, also using PEI as a modifier (Fig. 5) [134]. In the first step, $\mathrm{TiCl}_{4}$ was mixed with PEI, whose charged amino groups were protonated at a $\mathrm{pH}$ of 8 . The positively charged amino groups of PEI accelerated the hydrolysis of $\mathrm{TiCl}_{4}$ into $\mathrm{TiO}_{2}$-nanoparticles and stabilized them electrosterically. These amineterminated $\mathrm{TiO}_{2}$-nanoparticles with positive charge then attached to acid-treated SWCNTs, either via amide linkage or through electrostatic interaction. Another route has been suggested by Jerome et al. [135], who grafted MWCNTs with poly-2-vinylpyridine (P2VP) to form carboxylate terminated alkyl chains, onto which positively charged magnetic $\mathrm{Fe}_{3} \mathrm{O}_{4}$ nanoparticles were anchored. The main advantage of the polymer route is that the polymers provide a very dense, uniform distribution of either negative or positive charges over the entire CNT surface, which enables very dense assemblies of metal oxide nanoparticles.

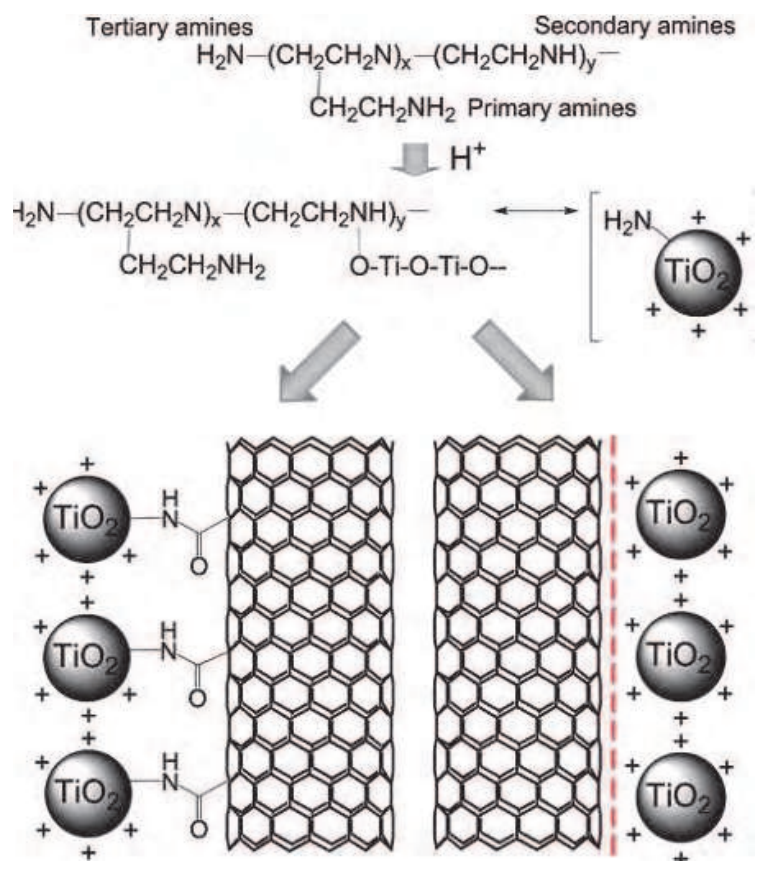

Fig. 5. Two-step process for the attachment of $\mathrm{TiO}_{2}$ nanoparticles to CNTs: (1) modification of the nanoparticles with positively charged PEI, containing primary, secondary, and tertiary amines, and (2) attachment via amide linkage or electrostatic interactions. (Courtesy of J. Sun et al. [134]) 
In summary, these few examples demonstrate the simplicity and feasibility of the ex situ approach, which remains the method of choice for the deposition of metal oxide nanoparticles. The main advantage is the possibility of using prepared nanoparticles with controlled morphology, structure, shape, and size, and, therefore, a good structure property relationship. The downside of this route, however, is the need to chemically modify either the CNTs or the metal oxide. This process is often work-intensive, and functionalization alters both the surface chemistry of the CNTs and also, particularly for SWCNTs, their physical properties. Furthermore, the use of predefined building blocks restricts the synthesis of novel hybrid materials and, thus, the development of new physical properties.

\subsection{In situ synthesis directly on the CNT surface}

The metal oxides or hydroxides can also be formed directly on the surface of pristine or modified CNTs. The main advantage of this route is that the metal oxide or hydroxide can be deposited as a continuous amorphous or single-crystalline film with controlled thickness, or as discrete units in the form of nanoparticles, nanorods, or nanobeads. Furthermore, the CNTs may act as a support to stabilize uncommon or even novel crystal phases or prevent crystal growth during crystallization and phase-transformation processes. Finally, a variety of chemical and physical synthesis techniques can be applied. The deposition can be carried out either in solution via electrochemical reduction of metal salts, electro- or electroless deposition, sol-gel processing, and hydrothermal treatment with supercritical solvents, or from the gas phase using chemical deposition (CVD or ALD) or physical deposition (laser ablation, electron beam deposition, thermal evaporation, or sputtering).

\subsubsection{Electrochemical techniques}

Electrochemistry is a powerful technique for the deposition of various metal oxide nanoparticles, as it enables effective control over nucleation and growth [136,137]. Most research has been conducted on the deposition of metal oxides, as they are the metal oxides of choice for applications like heterogeneous electrocatalyst, sensors, supercapacitors and so on. In general, metal oxide nanoparticles are obtained via reduction of metal complexes by chemical agents (chemical reduction), or by electrons (electrodeposition). The size of the metal oxide nanoparticles and their coverage on the sidewalls of CNTs can be controlled by the concentration of the metal salt and various electrochemical deposition parameters, including nucleation potential and deposition time [138].

\subsubsection{Chemical reduction and oxidation}

These techniques involve reactions, in which the reduction of the precursor is carried out with liquid or gaseous reducing agents with the aid of heat, light, ultrasound, microwave, or supercritical $\mathrm{CO}_{2}[139,140]$. As an example, Sivvakkumar et al. deposited $\mathrm{MnO}_{2}$ via chemical reduction of $\mathrm{KMnO}_{4}$ [141]. The authors suspended the CNTs in Na-p-toluene sulfonate and pyrrole, which polymerized with the aid of ultrasonication. $\mathrm{KMnO}_{4}$ was then slowly added and reduced with acetonitrile to form hydrous $\mathrm{MnO}_{2}$. A very elegant variation of this process is shown in Fig. 6 and uses $\mathrm{KMnO}_{4}$ as both the oxidizer and reactant [142]. In detail, pristine MWCNTs were first oxidized under reflux with $\mathrm{KMnO}_{4}$, which introduced exclusively hydroxyl groups on the sidewalls of CNTs, in contrast to other oxidation treatments, e.g., with oxidizing acids. These hydroxyl groups then acted as anchors for $\mathrm{Mn}^{7+}$ ions, which subsequently were reduced to $\mathrm{Mn}^{4+}$ with citric acid to 
form a coating of $\varepsilon-\mathrm{MnO}_{2}$. For comparison, a pretreatment of the CNTs in strong acids, which induces the formation of carboxyl groups, resulted instead in $\gamma-\mathrm{MnO}_{2}$ [143]. Therefore, this work provides an interesting example of the effect of the CNT surface chemistry on the crystal structure of the metal oxide coating. In contrast to $\mathrm{MnO}_{2}$, the deposition of other metal oxides typically requires oxidizing rather than reducing processes. For instance, Huang et al. added acid-treated CNTs to a solution containing ammonium metavanadate [144]. The adsorbed $\mathrm{VO}^{2+}$ ions were then oxidized with oxalic acid to $\mathrm{V}_{2} \mathrm{O}_{5}$. A different approach combined the reduction of cationic precursors by hydrogen with a water-in-oil microemulsion technique for the deposition of metal oxide nanoparticles [145]. Sun et al. used a slightly modified process [146]. The CNTs was mixed first with an aqueous solution of sodium dodecylbenzene sulfonate (NaD-DBS) and then with a mixture of Triton- $X$ and cyclohexane, which resulted in very small water droplets on the CNT surface. Upon adding zinc acetate as the metal precursor, the $\mathrm{Zn}^{2+}$ ions concentrated in the aqueous phase and then reacted with $\mathrm{NH}_{3}$ or $\mathrm{LiOH}$ to form spherical, hollow $\mathrm{ZnOH}$ nanoparticles. Subsequent calcinations oxidized them to create small and dense $\mathrm{ZnO}$ nanoparticles. In all cases, the microemulsion technique produced fine dispersions of small nanoparticles.
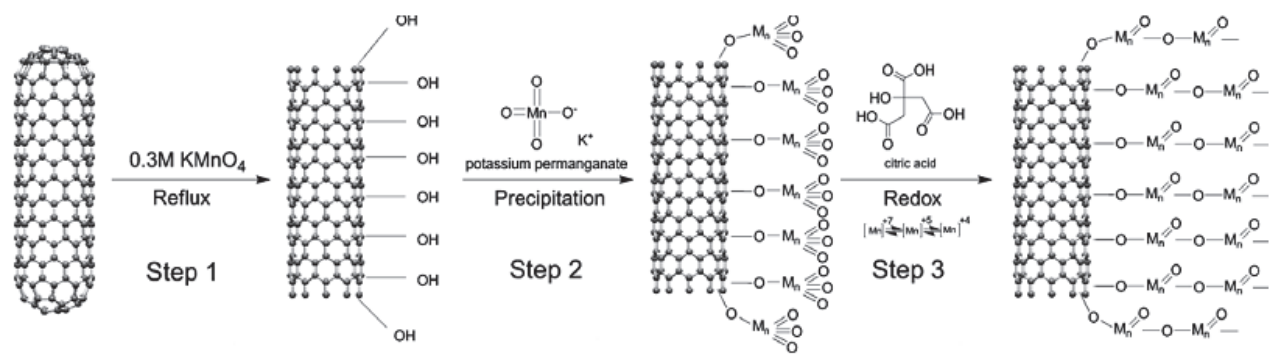

Fig. 6. Example of the deposition of $\mathrm{MnO}_{2}$ on CNTs via chemical reduction. The multistep process involves (1) the oxidation of MWCNTs with $\mathrm{KMnO}_{4}$ to form hydroxyl groups, (2) the precipitation of permanganate ions, and (3) their reduction with citric acid to $\mathrm{MnO}_{2}$. (Courtesy of X. Xie et al. [142])

\subsubsection{Electrodeposition}

Many of the above-mentioned reduction/oxidation techniques are very time-consuming and as such allow impurities in the bath solution to be incorporated into the inorganic phase. In contrast, electrodeposited nanoparticles, exhibit higher purities as well as a good adhesion to the CNT surface [138].

In most cases, simple van der Waals interactions between the CNTs and the metal oxide nanoparticles seem to be sufficient to provide strong enough adhesion. Although most research currently concentrates on the electrodeposition of metal nanoparticles, there have also been a few reports on electrodeposited metal oxides. As an example, $\mathrm{TiCl}_{3}$ was used as a precursor and electrolyte and was kept at $\mathrm{pH} 2.5$ with $\mathrm{HCl} / \mathrm{Na}_{2} \mathrm{CO}_{3}$. The deposition was then carried out via galvanostatic oxidation with $1 \mathrm{~mA} / \mathrm{cm}^{2}$ and resulted in a rather irregular and partial coating of a mixture of anatase and $\mathrm{TiO}_{2}-\mathrm{B}$ [147]. The galvanostatic approach $\left(3 \mathrm{~mA} / \mathrm{cm}^{2}\right)$ has also been applied to codeposit $\mathrm{Ni}$ and Co oxides from their 
nitrates, with $\mathrm{Pt}$ and saturated calomel as the counter electrodes and reference electrodes, respectively [148]. This was also demonstrated by Kim et al., who produced a continuous $3 \mathrm{~nm}$ thick coating of $\mathrm{RuO}_{2}$ via the potential cycling method while varying the potential from 200 to $1000 \mathrm{mV}$ with a scan rate of $50 \mathrm{mV} / \mathrm{s}$ [149]. They observed that the gas atmosphere during the postannealing process had a significant effect on the morphology of RuOx [150].

One advantage of this technique is that the electrodeposition occurs to the same extent on both the sidewalls of the tubes and the tips [151]. Consequently, the presence of carboxyl or hydroxyl groups as activators is not required. However, the major drawback of electrodeposition is that it is difficult to produce bulk quantities.

\subsubsection{Sol-gel process}

The sol-gel process is a versatile, solution-based process for producing various ceramic and glass materials in the form of nanoparticles, thin-film coatings, fibers, or aerogels and involves the transition of a liquid, colloidal "sol" into a solid "gel" phase [152]. The sol-gel process is a cheap and low-temperature technique that allows fine control of chemical composition and the introduction of lowest concentrations of finely dispersed dopants. One of the major drawbacks is that the product typically consists of an amorphous phase rather than defined crystals and, thus, requires crystallization and postannealing steps.

In general, the sol-gel process has emerged as the most common technique to synthesize CNT/metal oxide hybrids. Early attempts concentrated on the dispersion of CNTs within a matrix of metal oxide nanoparticles. Vincent et al. synthesized $\mathrm{TiO}_{2}$ nanoparticles using metal organic precursors and acetic acid as a gelator [153]. They observed that the dispersion of pristine CNTs was more stable when the $\mathrm{TiO}_{2}$ nanoparticles had been produced in the presence of the CNTs (in situ) compared with the simple mixing of the two materials. Upon reducing the amount of $\mathrm{TiO}_{2}$ with respect to CNTs, Jitianu et al. obtained a thin but rather irregular and partial coating of $\mathrm{TiO}_{2}$ on CNTs $[154,155]$. Typically, the thickness of the coating can be controlled by various parameters, such as the reaction time [156], the reaction composition, and the choice of metal precursor [157]. For instance, in the case of $\mathrm{TiO}_{2}$, the use of titanium tetraisopropoxide (TTIP) produced irregular coatings $[154,158]$, while tetraethoxy orthotitanate (TEOT) [154] or tetrabutoxy orthotitanate (TBOT) $[157,159]$ enabled a more uniform deposition. The sol-gel process was sometimes carried out under reflux [156], or with the aid of ultrasonication [160], microwave [161], or magnetic agitation [162], in order to enable faster and simultaneous nucleation resulting in a more homogeneous coating.

\subsubsection{Covalent}

These early works used pristine CNTs, whose hydrophobic nature provides little attractive interaction with the metal oxide and thus limits the quality of the coating. Similar to the ex situ approach, the most common approach to change the surface chemistry of CNTs is to treat them in strong oxidizing acids $\left(\mathrm{H}_{2} \mathrm{SO}_{4} / \mathrm{HNO}_{3}\right)$. This process introduces a variety of organic groups, with limited control over their number, type, and location, and causes surface etching and shortening of the tubes. Consequently, the metal oxide coatings on acidtreated CNTs were often nonuniform, although they provided better interaction in comparison with pristine CNTs. Despite these drawbacks, most researchers have used such acid-treated CNTs for various metal oxide coatings, including $\mathrm{SnO}_{2}$ [160,161,163-165], $\mathrm{TiO}_{2}$ [159,166-168], $\mathrm{RuO}_{2}$ [169,170], $\mathrm{CeO}_{2}$ [162], $\mathrm{NiO}$ [171], and mixed oxides [172]. 


\subsubsection{Noncovalent}

In a similar way to the ex situ approach, noncovalent attractions and п- $\Pi$ interactions can be used to grow the metal oxide on the surface of CNTs. Cao et al. modified CNTs with surfactants such as sodium dodecylsulfate (SDS) [173]. The hydrophobic aliphatic chain interacted with the surface of the CNTs, while the hydrophilic end attracted the metal ions of the $\mathrm{RuCl}_{3}$ precursor, which then reacted to form $\mathrm{RuO}_{2}$. Recently, this author has developed a nondestructive, simple process to coat pristine CNTs with $\mathrm{TiO}_{2}$ by using benzyl alcohol as a surfactant [174]. Benzyl alcohol adsorbs onto the CNTs' surface via ח-ח interactions with the alcohol's benzene ring, while simultaneously providing hydrophilic hydroxyl groups for the hydrolysis of the titanium precursor (TBOT) (Fig. 7). In contrast to the sample without benzyl alcohol (Fig. 7A), the addition of small amounts of benzyl alcohol resulted in a very uniform coating that covered the whole CNT surface. The work further showed that benzyl alcohol strongly affected the phase transition from anatase to rutile, providing very small and uniform rutile nanocrystals with very high specific surface areas $\left(60-100 \mathrm{~m}^{2} / \mathrm{g}\right)$ without too great a hindrance of the anatase to rutile transformation.

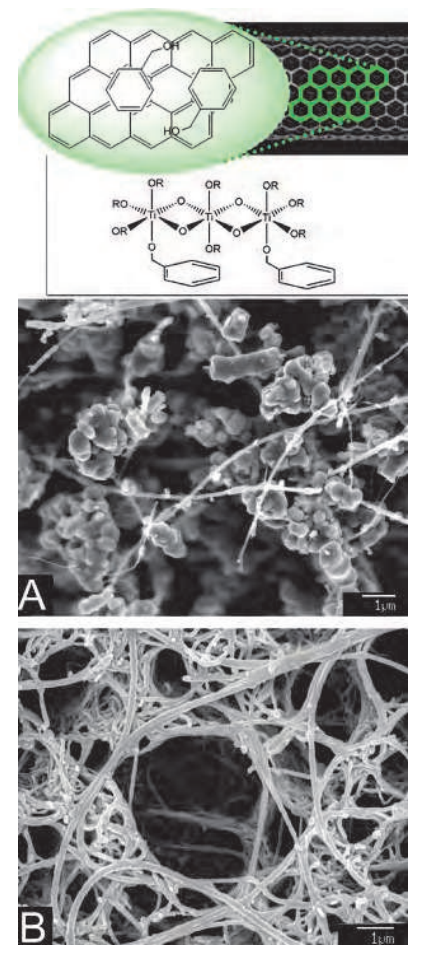

Fig. 7. (Top) Scheme of the beneficial role of benzyl alcohol in the in situ coating of pristine CNTs with $\mathrm{TiO}_{2}$. The benzene rings of the alcohol adsorb onto the CNT surface via חinteractions and at the same time provide a high density of hydroxyl groups for the hydrolysis of the titanium precursor directly on the CNT surface. (Bottom) SEM images of pristine MWCNTs (A) without the use of benzyl alcohol and (B) with a titanium-to-benzyl alcohol molar ratio of 5. (Courtesy of D. Eder et al. [174]) 


\subsubsection{Electrostatic}

In contrast to the ex situ approach, the use of electrostatic interactions for the in situ sol-gel route has been demonstrated for a few metal oxides. As an example, Hernadi et al. used CNTs that had been pretreated with SDS, dried, and redispersed in 2-propanol [175]. Using metal halides as precursors, the authors could successfully produce coatings of $\mathrm{Al}_{2} \mathrm{O}_{3}$ and $\mathrm{TiO}_{2}$. Vietmeyer et al. used acid-treated CNTs to attract $\mathrm{Zn}^{2+}$ ions (using zinc acetate), which then reacted with $\mathrm{LiOH}$ in an ice-water bath to form $\mathrm{ZnO}$ nanoparticles [176]. While some metal oxide nanoparticles were attached to the CNT surface and tips, most of the nanoparticles formed large clusters rather than a continuous coating. For comparison, Jiang et al. enhanced the negative charge on the surface of acid-treated CNTs by simply depositing a thin layer of SDS and carried out the same reaction with zinc acetate and $\mathrm{LiOH}$ [177]. This surface modification significantly enhanced the attractive interactions with the metal ions and led to a more uniform coating with $\mathrm{ZnO}$ crystals.

\subsubsection{Hydrothermal and aerosol techniques}

In recent years, many organic-inorganic hybrids have been produced by hydrothermal techniques [178]. In contrast to standard sol-gel routes, the hydrothermal method typically enables the formation of crystalline particles or films without the need for postannealing and calcinations. Furthermore, the forced crystallization enables the formation of metal oxide nanowires and nanorods [179].

\subsubsection{Vapor-assisted, polyol-assisted process}

In this simplest case of hydrothermal synthesis, pristine or acid-treated CNTs were added to an aqueous solution of the precursor and treated in an autoclave at temperatures between 100 and $240{ }^{\circ} \mathrm{C}$ to produce crystalline films of $\mathrm{ZnO}$ [180], $\mathrm{TiO}_{2}$ [181], or $\mathrm{Fe}_{2} \mathrm{O}_{3}$ [182]. These works consistently produced dense coatings of spherical or slightly elongated nanoparticles. Zhang et al. used aligned CNTs, which they precoated with a thin, amorphous layer of ZnO via magnetron sputtering [183]. Then they dissolved a fine $\mathrm{ZnO}$ powder in $\mathrm{NaOH}$ at a $\mathrm{pH}$ of $10-12$, which provided a saturated solution of $\mathrm{Zn}(\mathrm{OH})_{4}{ }^{2-}$. The modified CNT carpet was then placed top-down in an autoclave, floating on the precursor solution. By keeping the reaction at a temperature of $100{ }^{\circ} \mathrm{C}$ for several hours, the Zn precursor nucleated on the CNT-ZnO film to grow ZnO nanowires perpendicular to the CNTs, with a thickness of $30-70 \mathrm{~nm}$ and lengths of up to $0.5 \mu \mathrm{m}$ (Fig. 8).

In general, specific molecules provide efficient control of the crystal size of the nanoparticles, which hinder the crystal growth by steric configuration (capping agents). For example, Yu et al. dissolved copper acetate in water and diethylene glycol and added acidtreated CNTs $[184,185]$. Upon heating in an autoclave at $180{ }^{\circ} \mathrm{C}$, the diethylene glycolcapped copper species condensed to $\mathrm{CuOx}$ and nucleated to form small $\mathrm{Cu}_{2} \mathrm{O}$ crystals. After a reaction time of $2 \mathrm{~h}$, the crystals were $5-10 \mathrm{~nm}$ in diameter and covered by an amorphous layer. Similarly, small crystals of $\mathrm{Fe}_{3} \mathrm{O}_{4}$ were produced by Jia et al., who used polyethylene glycol (PEG) and $\mathrm{FeCl}_{3}$ and a reaction temperature of $200{ }^{\circ} \mathrm{C}$ [186]. However, the $5 \mathrm{~nm}$ crystals agglomerated to about $180 \mathrm{~nm}$ aggregates (nanobeads), which attached preferably to the carboxyl groups on the surface of acid-treated CNTs. Consequently, the magnetite nanobeads were concentrated at the tips of the CNTs and acted as a glue to form heterojunctions between the CNTs (Fig. 9). 


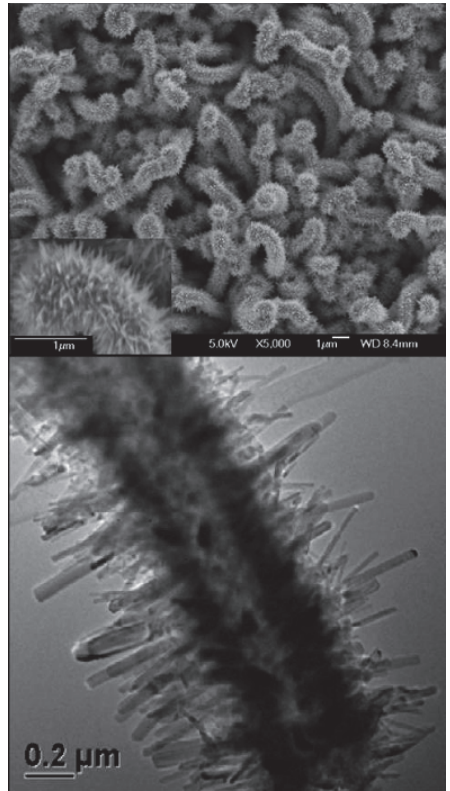

Fig. 8. Example of the hydrothermal synthesis: growth of $\mathrm{ZnO}$ nanowires perpendicular to MWCNTs. (Courtesy of W. D. Zhang et al. [183])

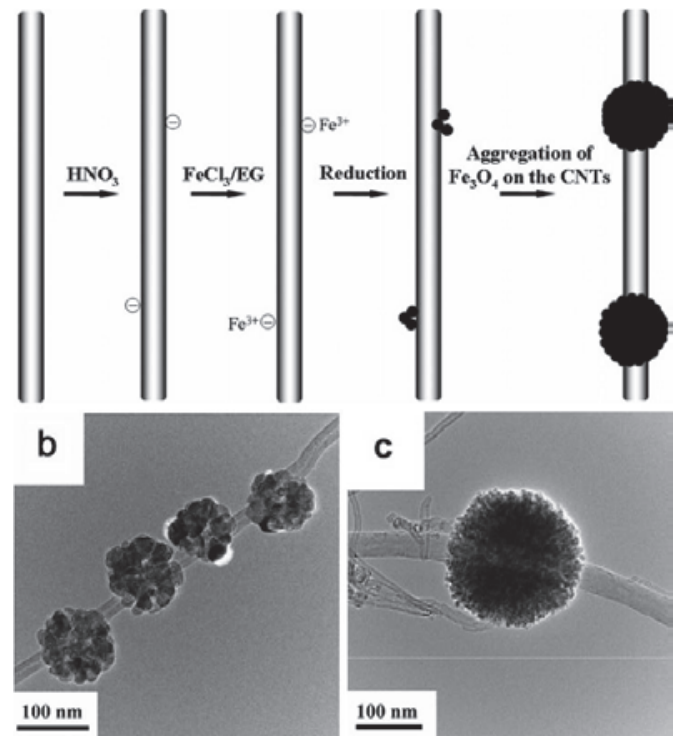

Fig. 9. Example of a polyol-assisted hydrothermal deposition of $\mathrm{Fe}_{3} \mathrm{O}_{4}$ on acid-treated MWCNTs. Polyethylene glycol (PEG) was used to reduce $\mathrm{FeCl}_{3}$ and to control the size of the magnetite nanoparticles, which formed large aggregates (nanobeads) near the carboxyl groups on the CNT surface. (Courtesy of B. P. Jia et al. [186]) 


\subsubsection{Supercritical solvent}

A very important hydrothermal method involves the use of supercritical $\mathrm{CO}_{2}$ as an antisolvent that reduces the solvent strength of ethanol, resulting in the precipitation of the oxide due to high saturation. Using metal nitrates or halides, this method has been applied to deposit $\mathrm{Eu}_{2} \mathrm{O}_{3}$ [187], $\mathrm{CeO}_{2}$ [188], $\mathrm{La}_{2} \mathrm{O}_{3}$ [188], $\mathrm{Al}_{2} \mathrm{O}_{3}$ [188], $\mathrm{SnO}_{2}$ [189,190], and $\mathrm{Fe}_{2} \mathrm{O}_{3}$ [191] onto pristine CNTs. Sun et al. used supercritical ethylenediamine as a solvent to produce thin coatings of $\mathrm{RuO}_{2}$ [192]. They also observed various morphologies and structures of cerium oxide by simply changing the reaction temperature [188]. For instance, the authors could alter the composition of cerium oxide from preferentially $\mathrm{Ce}_{2} \mathrm{O}_{3}$ at $120{ }^{\circ} \mathrm{C}$ to $\mathrm{CeO}_{2}$ at $150{ }^{\circ} \mathrm{C}$. In contrast, a reaction temperature of $120^{\circ} \mathrm{C}$ was needed to obtain a coating of $\mathrm{SnO}_{2}$, while at $35^{\circ} \mathrm{C}$ the oxide was only encapsulated [190].

\subsubsection{Gas-phase deposition}

Chemical and physical vapor deposition techniques are among the most common methods to produce metal oxide nanomaterials, as they provide excellent control over the size, shape, and uniformity of the oxide material. Furthermore, it is possible to deposit thin, continuous films on carbon substrates, without altering the $3 \mathrm{D}$ integrity of vertically aligned CNTs. This section provides examples of the synthesis of various CNT/metal oxide hybrids using physical techniques, such as evaporation, sputtering, and pulsed laser deposition (PLD), and chemical methods, including chemical vapor deposition (CVD) and atomic layer deposition (ALD).

\subsubsection{Evaporation and sputtering}

Physical vapor deposition involves the evaporation of material in a crucible under high vacuum, using either resistive heating (thermal evaporation) or electron bombardment (electron beam deposition). In contrast, sputtering (magnetron and radio frequency, RF) relies on plasma (typically argon) to bombard the target material, which can be kept at a relatively low temperature. Reactive sputtering involves a small amount of oxygen, which reacts with the sputtered material to deposit oxides. The deposition of metal oxides via thermal evaporation has been demonstrated by Kim et al., who mixed annealed CNTs with Zn powder in a ratio of 1:12 [193]. Depending on the reaction temperature, the $\mathrm{Zn}$ particles reacted with oxygen impurities in argon to form a coating on the CNTs consisting either of spherical particles $\left(450^{\circ} \mathrm{C}\right)$, nanowires $\left(800^{\circ} \mathrm{C}\right)$, or short nanorods $\left(900^{\circ} \mathrm{C}\right)$. RF or magnetron sputtering has been used to deposit RuOx, [194] and $\mathrm{ZnO}$ [195]. Furthermore, Jin et al. have cosputtered $\mathrm{Ba}$ and $\mathrm{Sr}$ in an oxygen atmosphere to obtain a $\mathrm{BaO} / \mathrm{SrO}$ coating [196]. In most of these works, the coating around the CNTs was generally conformal, although in the case of vertically aligned CNTs ("carpet"), the metal oxide material was deposited predominantly along the top of the carpet. Interestingly, Fang et al. observed that the distribution of $\mathrm{RuO}_{2}$ particles on vertically aligned CNTs was significantly better on nitrogen-doped CNTs compared with pure CNTs [197]. It is well-known that the incorporation of nitrogen into the sp2-type walls of CNTs causes many structural defects (pyridine-like bonding) due to the different valence of nitrogen ions. It seems that these defects are more reactive toward the adsorption of $\mathrm{RuO}_{2}$ than the graphitic walls of pure CNTs and allow a uniform dispersion along the sidewalls of nitrogendoped CNTs (Fig. 10).

In summary, sputtered films typically have a better adhesion to the substrate than evaporated films and a composition closer to that of the source material. Sputtering also enables the deposition of materials with very high melting points and can be performed 
"top-down", while evaporation must be operated "bottom-up". On the other hand, evaporation techniques typically offer better structural and morphological control and more flexible deposition rates.

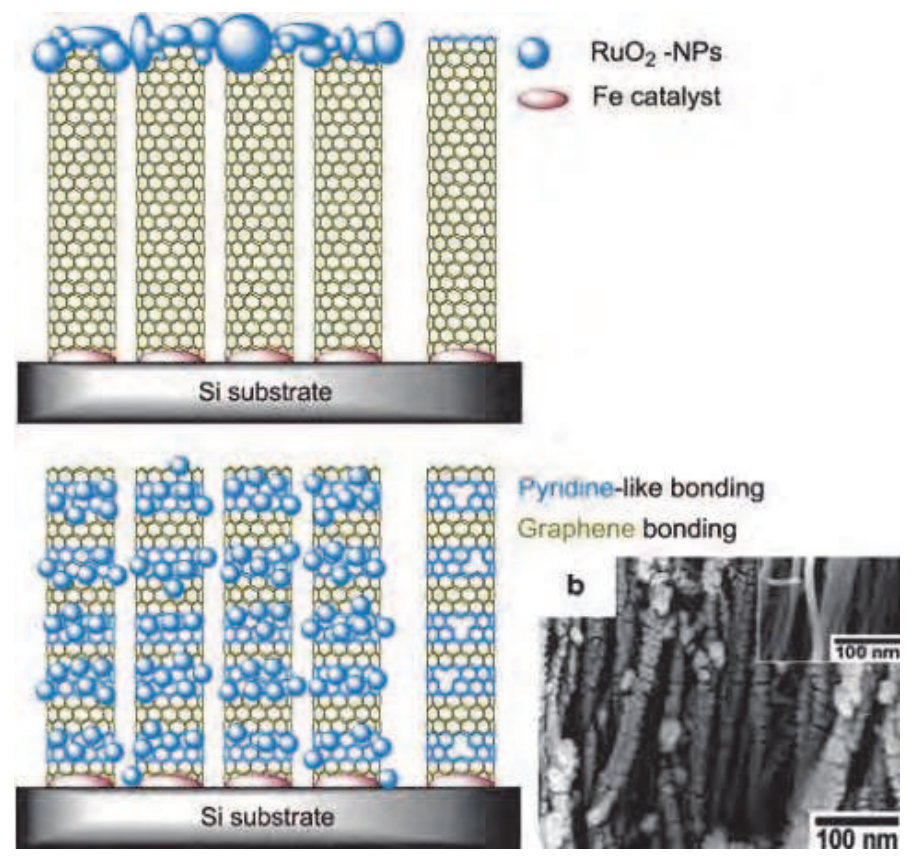

Fig. 10. Scheme of the deposition of $\mathrm{RuO}_{2}$ nanoparticles on aligned CNTs (top) and nitrogendoped CNTs (N-CNTs, bottom) via magnetron sputtering. The pyridine-like defects in the $\mathrm{N}-\mathrm{CNTs}$ provide a stronger interaction with $\mathrm{RuO}_{2}$ and a more uniform dispersion along the sidewalls. (Courtesy of W. C. Fang et al. [197])

\subsubsection{Pulsed laser deposition}

Pulsed laser deposition (PLD) is related to the evaporation techniques but utilizes a highpower pulsed laser beam. The directed laser pulse is absorbed by the target, vaporizes the material, and creates a plasma plume containing various energetic species, such as atoms, molecules, electrons, ions, clusters, particulates, and molten globules, which then expand into the vacuum and deposit on a typically hot substrate to nucleate and grow as a thin film. This process can occur in ultrahigh vacuum or in the presence of a background gas, such as oxygen, which is commonly used when depositing oxides. Ikuno et al. used individual MWCNTs (grown by arc discharge), which were attached to a molybdenum plate via electrophoresis. A pulsed Nd:YAG (yttrium aluminum garnet) laser with a wavelength of $355 \mathrm{~nm}$ was focused onto a target at a repetition rate of $10 \mathrm{~Hz}$. A single-crystalline $\mathrm{Si}$ wafer and pellets of $\mathrm{Zr}, \mathrm{Hf}, \mathrm{Al}$, $\mathrm{ZnO}, \mathrm{Au}$, and $\mathrm{Ti}$ were used as targets for the coating of $\mathrm{SiOx}, \mathrm{ZrOx}, \mathrm{HfOx}, \mathrm{AlOx}$, and $\mathrm{ZnOx}$ $[198,199]$. The advantages of this technique over other thin-film deposition methods include the relatively simple basic setup and the operation at room temperature. On the other hand, PLD has a lower average deposition rate than other deposition techniques, such as CVD or evaporation/sputtering techniques, but is faster than ALD. 


\subsubsection{Chemical vapor deposition}

Chemical vapor deposition (CVD) is a versatile technique often used in the semiconductor industry that involves the growth of a solid material from the gas phase via chemical reaction at the surface of a substrate. In contrast to high-pressure/high-temperature synthesis, the CVD technique typically operates at medium temperatures $\left(600-800{ }^{\circ} \mathrm{C}\right)$ and at slightly reduced atmospheric pressures. Because CVD utilizes reagents of very high purity, the technique is capable of synthesizing crystals with controlled purity and composition. Other advantages of CVD include the high deposition rate, good degree of control (purity and composition), and easy scalability. However, due to the fast deposition, it is difficult to achieve uniform and defect-free coatings when scaling down to a few nanometers. Several groups have used CVD to synthesize CNT-metal oxide hybrids with $\mathrm{SnO}_{2}$ [200] and $\mathrm{RuO}_{2}$ [201]. Kuang et al. deposited acid-treated MWCNTs on a Si waver and heated them to $550{ }^{\circ} \mathrm{C}$ in a $\mathrm{SnH}_{4}$-containing $\mathrm{N}_{2}$ atmosphere [200]. At this temperature, the precursor decomposed, attached to the functional groups of the CNTs, and reacted with the oxygen impurities to produce $\mathrm{SnO}_{2}$. In a similar way, CNTs/ $\mathrm{RuO}_{2}$ [150], CNTs/ $\mathrm{Co}_{3} \mathrm{O}_{4}$ [202] and CNTs/ZnO [203-205] have been synthesized by directly coating of prepared CNTs. On the other hand, An example of the in situ growth of CNTs is the work of Liu et al., who used a water-assisted CVD process to produce CNTs with a $\mathrm{ZnO}$ coating [206]. Most of the $\mathrm{ZnO}$ coating was observed at the tip of the CNTs. An interesting alternative to $\mathrm{ZnO}$ was demonstrated by Ho et al. [207]. The authors used $\mathrm{Ni}$ catalyst particles, supported on $\mathrm{MgO}$, which were deposited on a Si wafer and placed inside a tube furnace. $\mathrm{ZnO}$ powder was put inside a thin ceramic tube, whose ends were covered with $\mathrm{Al}$ foil, and placed inside the reactor tube, close to the catalyst powder. Upon reaching a certain temperature $\left(300-350^{\circ} \mathrm{C}\right)$, assisted via a plasma-enhanced CVD technique, CNTs began to grow on the Ni particles and kept growing as the temperature was steadily increased to 700 ${ }^{\circ} \mathrm{C}$ over a period of about 6-7min. At this temperature, the $\mathrm{Al}$ foil melted and exposed the $\mathrm{ZnO}$ powder, which was instantaneously transformed to $\mathrm{Zn}$ vapor via carbothermal reduction and deposited on the still-growing CNTs as a thin coating of $\mathrm{ZnO}$.

\subsubsection{Atomic layer deposition}

In contrast to CVD, the precursors for atomic layer deposition (ALD) are kept separate and exposed sequentially. Ideally, each precursor forms a monolayer on the substrate, and the excess vapor is removed before the next precursor is introduced. This process is then repeated until the deposited film reaches the desired thickness. Hence, ALD film growth is self-limiting and based on surface reactions, which enables deposition control on the atomic scale. As an example, Gomathi et al. used metal chloride precursors to coat acid-treated MWCNTs with $\mathrm{TiO}_{2}$ and $\mathrm{Al}_{2} \mathrm{O}_{3}$ [208]. Similarly, Javey et al. demonstrated coatings of $\mathrm{ZrO}_{2}$ as thin as $8 \mathrm{~nm}$ covering the top of horizontally attached SWCNTs for device applications [209]. ALD has unique advantages over other thin-film deposition techniques, as it can be operated at low temperatures and allows exact control over the thickness of the deposited coating. However, because of the sequential exposure of the precursors, the technique has the lowest deposition rate compared with CVD and PLD.

\section{Properties and potential applications of CNTs/metal oxide hybrids}

The improved performances of CNT/metal oxide hybrids are demonstrated in many applications, such as photocatalysis, electrocatalysis, and environmental catalysis, gas sensors and chemical sensors, supercapacitors and batteries, and field emission devices. In 
the section, some applications of electrocatalysis, electrochemical sensors, supercapacitors and batteries are highlighted and summarized as follow.

\subsection{Electrocatalysis}

Electrocatalyst is a new catalyst depending on electric energy. Which accelerate the reactions on the interface between electrode and electrolyte. It has significance in research work and also has important application value on organic wastewater treatment and degradation, electrolytic desulfurization, and electroreduction study. As an electrocatalyst, two basic conditions are necessary: (a) electrical conductivity and transfer free electron well; (b) efficient catalytic activity towards target substrate. Metal, especially noble metal, and some metal oxide or hydroxide are widely used as electrocatalysts [210]. In contrast, some common transition metal oxides or hydroxides, such as $\mathrm{TiO}_{2}, \mathrm{SnO}_{2}, \mathrm{Ni}(\mathrm{OH})_{2}$, have many advantages including low cost, facile preparation, and thus are more interesting for wide study. CNTs endows CNT/metal oxide or hydroxide composites enhancement on electrocatalysis duo to electric conductivity and fast electron transfer.

For example, Qiao et al. reported that the MWCNTs/Ni(OH $)_{2}-\mathrm{Ni}$ electrode showed better catalytic effect on the oxidation of $\mathrm{CH}_{4}$ in $1.0 \mathrm{M} \mathrm{NaOH}$ than $\mathrm{Ni}(\mathrm{OH})_{2}-\mathrm{Ni}$ electrode [211]. $\mathrm{ZnO}-\mathrm{NWs}$ /MWCNTs nanocomposite had been prepared via a hydrothermal process by Mo et al., and showed remarkable electrocatalytic activity towards $\mathrm{H}_{2} \mathrm{O}_{2}$ by comparing with bare MWCNTs [212]. Subseguently, Ma et al. discovered that ZnO-MWCNTs/Nafion film showed fast and excellent electrocatalytic activity to not only $\mathrm{H}_{2} \mathrm{O}_{2}$, also trichloroacetic acid [213]. Other metal oxide or hydroxide, such as $\mathrm{FeOOH}$ [214] and cobalt-coordinated polypyrrole [215], have been reported have obvious electrocatalysis towards oxygen reduction reaction. Recently, we synthesized CNTs/nickel glycolate polymer core-shell heterostructures and found that the composite have significant electrocatalysis towards glucose in $0.5 \mathrm{M} \mathrm{NaOH}$, and catalytic activity dependent obviously on the thickeness of the nickel glycolate polymer on MWCNTs (Fig. 11).

The role of CNTs is often attributed to their ability to stabilize highly dispersed catalyst nanoclusters, resulting in higher specific surface areas. So, There is also important significant for fuel cell and biosensor to study further electrocatalysis of CNTs/metal oxide or hydroxide composites.
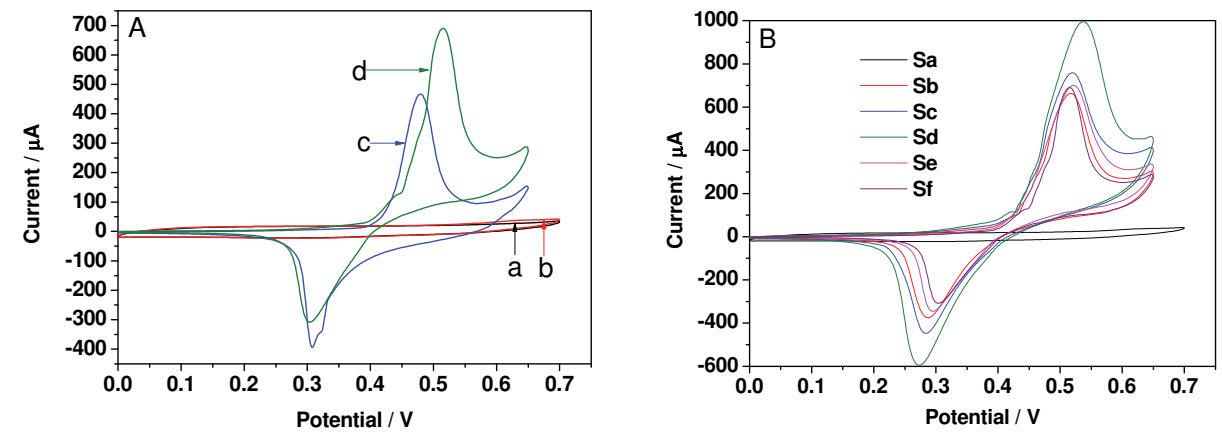

Fig. 11. A) CVs of MWCNTs (a,b) and MWCNT/nickel glycolate polymer core-shell heterostructures in $0.5 \mathrm{M} \mathrm{NaOH}$ with absence of $(\mathrm{a}, \mathrm{c})$ and presence of $(\mathrm{b}, \mathrm{d}) 1 \mathrm{mM}$ glucose. $\mathrm{B})$ The electrocatalysis activity difference of the nanocomposites with different thickness of glycolate polymer shell towards glucose. 


\subsection{Electrochemical sensors}

Metal oxide semiconductors (MOS) are prominent examples of sensing materials in gas sensors, as their electrical properties are highly affected by the surrounding gas environment. For instance, tungsten trioxide $\left(\mathrm{WO}_{3}\right)$ shows sensitivity to pollutants such as $\mathrm{SO}_{2}, \mathrm{H}_{2} \mathrm{~S}, \mathrm{NO}$, and $\mathrm{NH}_{3}[216,217]$, while $\mathrm{SnO}_{2}$ is sensitive to $\mathrm{NOx}, \mathrm{CO}$, ethanol, and $\mathrm{C}_{2} \mathrm{H}_{4}$ [218]. However, their sensing properties often suffer degradation due to growth and aggregation. In contrast with metal oxide sensors, CNTs exhibit excellent adsorption properties due to their high specific surface area, which provides a large number of active surface sites [219-221]. As the CNTs' electric properties are effectively altered by very small amounts of adsorbed gas molecules, the CNT gas sensor can be operated at temperatures close to room temperature. However, as MWCNTs are not very sensitive to ambient gas, the use of CNTs as gas sensors is mainly restricted to SWCNTs. Furthermore, due to their long recovery times, CNT-based sensors typically need reactivation.

CNTs/MOS hybrid composite sensors have been fabricated and investigated widely. These sensors don't noly improve the efficiency of the metal oxide based sensors, such as enhanced sensitivity and selectivity to target gases, reduced response and recovery times, but also are operated at lowered temperature, even room temperature. Similar to core/shell heterostructures like MOS/CdS, CNT/MOS hybrids have shown improved photoluminescent quantum efficiencies and enhanced gas-sensing properties including reduced response and recovery times $[163,222]$. So far, $\mathrm{CNT} / \mathrm{SnO}_{2}$ has been tested for detection of $\mathrm{CO}$ [172], $\mathrm{NO}_{2}$ [201,203], $\mathrm{NH}_{3}$ [223], formaldehyde [224], and ethanol [225]. Wei et al. used a sol-gel process to coat pristine SWCNTs with $\mathrm{SnO}_{2}$ and investigated the gassensing performance for $\mathrm{NO}_{2}$ at room temperature [165]. They observed considerably enhanced sensitivities $\left(\Delta \mathrm{R} / \Delta \mathrm{C}\right.$, Fig. 12) compared with the pure $\mathrm{SnO}_{2}$ sensor. Because the morphology and surface area of the hybrid sensors were similar to those of the pure $\mathrm{SnO}_{2}$, and the observed sensitivities increased with increasing CNT loading, the authors concluded that the advanced sensing behavior originated from a common interface with CNTs. In contrast to conventional $\mathrm{SnO}_{2}$ sensors, which typically operate at temperatures between 200 and $500{ }^{\circ} \mathrm{C}$, the SWCNT/SnO ${ }_{2}$ hybrid gas sensors could indeed be operated at room temperature. When the $\mathrm{NO}_{2}$ gas molecules adsorb on the surface of pure $\mathrm{SnO}_{2}$, they extract electrons, leaving the oxide surface positively charged. This leads to the formation of a depletion zone and to an increase in the sensor resistance. In the $\mathrm{CNT} / \mathrm{SnO}_{2}$ hybrid sensor, the electric properties of the oxide are strongly enhanced by the highly conducting CNTs. Consequently, the sensor resistance is dominated by the Schottky barrier at the interface between the n-type $\mathrm{SnO}_{2}$ grains and the p-type CNTs, causing the formation of additional depletion layers, which then amplifies the increase in resistance upon $\mathrm{NO}_{2}$ adsorption and enables the operation of the gas sensor at room temperature.

As CNTs/metal oxide hybrid sensors emerges, some of which were investigated to applied in liquid sensing, especially biosensors including glucose sensor, hydrogen peroxide, hydrazine sensor and nitrite detection etc. The sensors have significant potential application in biology and medicine because of unavoidable drawbacks of enzyme sensor, such as temperature, $\mathrm{PH}$, and unicity. More and more CNTs/metal oxide hybrids were reported to be used as various sensors in liquid.

For instance, Jiang et al. reported a highly sensitive nonenzymatic glucose sensor based on $\mathrm{CuO}$ nanoparticles-modified carbon nanotube electrode by sputtering deposition method [226]. The $\mathrm{CuO} / \mathrm{MWCNTs}$ electrode exhibits an enhanced electrocatalytic property, lowworking potential, high sensitivity, excellent selectivity, good stability, and fast amperometric 
sensing towards oxidation of glucose, thus is promising for the future development of nonenzymatic glucose sensors. Glucose was also detected with $\mathrm{CNT} / \mathrm{Fe}_{3} \mathrm{O}_{4}$ hybrids electrochemically doped glucose oxidase reported by Liu et al. [227] The $\mathrm{PA}-\mathrm{Fe}_{3} \mathrm{O}_{4}-\mathrm{CNT}$ based glucose sensor shows much higher sensitivity and linearity than the $\mathrm{PA}-\mathrm{Fe}_{3} \mathrm{O}_{4}$-based sensor, indicating that CNTs significantly enhance the performances of the biosensor. A novel hydrazine electrochemical sensor based on a carbon nanotube-wired $\mathrm{ZnO}$ nanoflowermodified electrode was reported via a simple process (ammonia-evaporation-induced synthetic method) by Fang et al. [228]. The authors observed that an optimized limit of detection of $0.18 \mu \mathrm{M}$ at a signal-to-noise ratio of 3 and with a fast response time (within $3 \mathrm{~s}$ ).
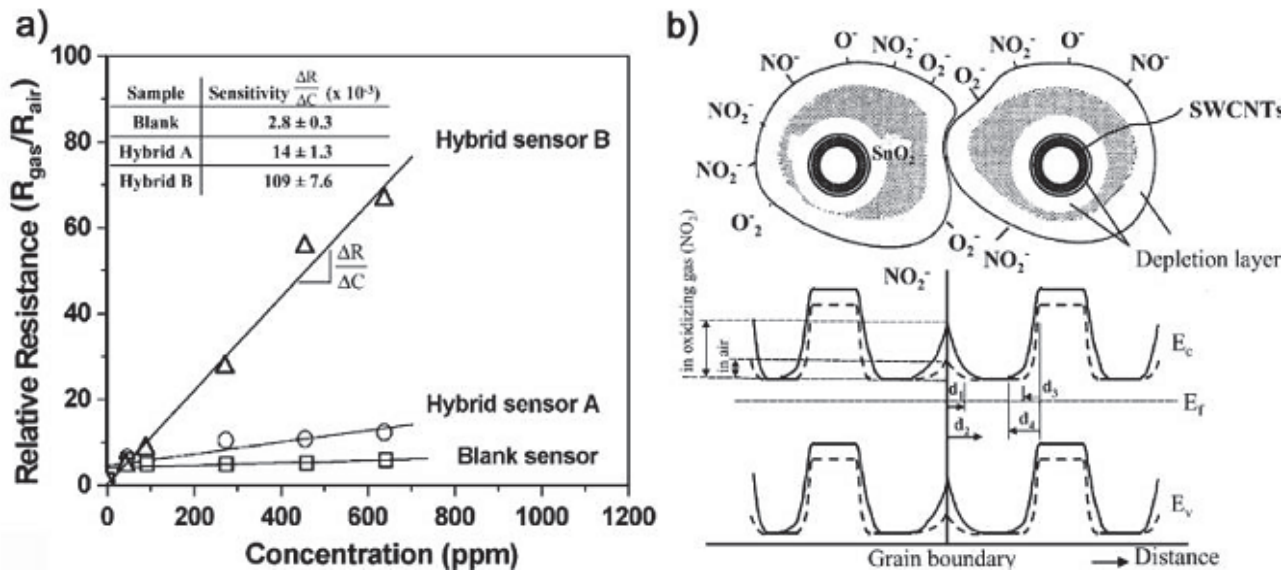

Fig. 12. Example of $\mathrm{CNT}-\mathrm{SnO}_{2}$ hybrid in gas sensors. (a) Relative resistances versus $\mathrm{NO}_{2} /$ air gas concentrations of $\mathrm{SnO}_{2}$ and hybrids with low (A) and high (B) concentrations of CNTs at room temperature. The sensitivities $(\Delta \mathrm{R} / \Delta \mathrm{C})$ increase considerably with increasing $C N T$ concentration. (b) Scheme of the presence of depletion zones near the CNT oxide interface. (Courtesy of B.Y. Wei et al. [165])

\subsection{Supercapacitors and batteries}

Reliable and affordable electricity storage is a prerequisite for optimizing the integration of renewable energy systems. Energy storage, therefore, has a pivotal role to play in the effort to combine a future, sustainable energy supply with the standards of technical services and products. For both stationary and transport applications, energy storage is of growing importance as it enables the smoothing of transient and/or intermittent loads and the downsizing of base-load capacity with substantial potential for energy and cost savings. The extended lifetime of batteries in handheld devices is credited not only to higher energy densities but also to a simultaneous reduction of energy consumption of the portable devices. In contrast, the electric vehicle has failed to become the accepted mode of transportation mainly because of the battery. Short distances between recharging and a limited service life of the battery are to blame, but also the incredible weight and volume of the batteries. Electrochemical capacitors (ECs) are energy-storage devices that possess higher energy and power density than conventional dielectric capacitors and batteries and are used in applications including electric vehicles, noninterruptible power supplies, dc power systems, lightweight electronic fuses, memory backups, and solar batteries [229]. The 
challenges for these applications concern limitations in volumetric/gravimetric power densities and RC time, long life, safety, simplicity of design, cost, and the possibility of recharging, and can only be accomplished by specially designed materials.

According to the mechanism of energy storage, ECs can be categorized into two classes [229]: (a) electrochemical double layer capacitors (EDLC), based on double-layer capacitance due to charge separation at the electrode/electrolyte interface, which thereby need materials with high specific surface area (e.g., activated carbon, CNTs), and (b) pseudocapacitors or supercapacitors, based on the pseudocapacitance of faradaic processes in active electrode materials such as transition metal oxides and conducting polymers.

Because of their exceptional electronic properties, which allow ballistic transport of electrons over long nanotube lengths, CNTs have been considered a most promising candidate for electrochemical capacitors [230,231]. However, pure CNTs possess a rather low specific capacitance, typically about 10-40 F/g, which depends on the microtexture, purity, and electrolyte [231]. A considerable enhancement can be expected from the combination of CNTs with an electroactive material, which provides the additional pseudocapacitance while each tube acts as a minute electrode. the electrochemical stability of transition metal oxides makes them a better choice, provided they are highly conducting. A wide range of oxides has been investigated for use in CNT hybrids, including $\mathrm{NiO}[171,232,233], \mathrm{MnO}_{2}$ [234-237], $\mathrm{V}_{2} \mathrm{O}_{5}$ [238,239], and $\mathrm{RuO}_{2}[169,192,194]$. In all of these studies, the synergistic effects of CNT oxide hybrids have shown a considerable improvement of the otherwise poor electric properties and deficient charge transfer channels of the pure oxide.

Among these transition metal oxides, ruthenium oxides are regarded as the most promising electrode material for supercapacitor applications due to their high specific capacitance, highly reversible redox reactions, wide potential window, and very long cycle life [192]. Park et al. reported a specific capacitance for $\mathrm{CNT} / \mathrm{RuO}_{2}(13 \mathrm{wt} \%)$ of $450 \mathrm{~F} / \mathrm{g}$ at a potential scan rate of $20 \mathrm{mV} \mathrm{s}^{-1}$, which could be further enhanced, by using hydrous ruthenium oxide and functionalized CNTs, to $800 \mathrm{~F} / \mathrm{g}$ [170]. Reducing the thickness of the $\mathrm{RuO}_{2}$ layer to $3 \mathrm{~nm}$ led to an even higher capacitance $\left(1170 \mathrm{~F} / \mathrm{g}\right.$ at a potential scan rate of $\left.10 \mathrm{mV} \mathrm{s}^{-1}\right)$ [149]. All of these studies also demonstrated longer lifetimes and greater stabilities and rate capabilities, while the specific capacitances were in general considerably higher than those observed for pure MWCNTs $(<80 \mathrm{~F} / \mathrm{g})$ or pure $\mathrm{RuO}_{2}(<400 \mathrm{~F} / \mathrm{g})$.

In view of the rather high costs and environmental issues concerning $\mathrm{RuO}_{2}$, and despite the lower specific capacitances, there has been a clear trend toward the use of hydrous manganese oxides in the past few years. Xie et al. produced a $\mathrm{CNT} / \mathrm{MnO}_{2}$ hybrid by in situ reduction of $\mathrm{KMnO}_{4}$ on MWCNTs with citric acid and observed that the specific capacitance increased from 18 to $190 \mathrm{~F} / \mathrm{g}$ [140]. Zhang et al. electrodeposited $\mathrm{MnO}_{2}$ "nanoflowers" onto the surface of vertical CNT arrays and obtained capacitances of about $200 \mathrm{~F} / \mathrm{g}$, as well as excellent rate capabilities $(50.8 \%$, capacity retention at $77 \mathrm{~A} / \mathrm{g})$ and a long cycle life $(3 \%$ capacity loss after 20000 charge/discharge cycles) [236]. The authors proposed a model for the improved electrochemical storage characteristics based on high electronic conductivity in CNTs. In this model, the geometry of the $\mathrm{MnO}_{2}$ nanoflowers and their hierarchical localization at $\mathrm{CNT}$ junctions limits the diffusion length of ions within the $\mathrm{MnO}_{2}$ phase during the charge/discharge process and enhances the ionic conductivity of the hybrid.

To maximize the electrochemical utilization of the supercapacitor, it is desirable to (a) use a low loading of metal oxide and (b) increase the interfacial area between CNTs and metal oxide. Consequently, the preparation of a thin, uniform, connected coating on CNTs is expected to improve the specific capacitance significantly. This was confirmed by Nam et al., 
who observed increasing capacitances with decreasing $\mathrm{NiO}$ content and thus coating thickness [233].

A promising approach to enhance the capacitive performance has recently been reported by Sivakkumar et al., who synthesized a ternary hybrid of $\mathrm{CNT} /$ polypyrrole/hydrous $\mathrm{MnO}_{2}$, which showed a significantly higher specific capacitance $(280 \mathrm{~F} / \mathrm{g})$ compared to the binary $\mathrm{CNT} / \mathrm{MnO}_{2}(150 \mathrm{~F} / \mathrm{g})$ [141]. The increase in capacitance is believed to be due to the better dispersion of hydrous $\mathrm{MnO}_{2}$ in the composite electrode. However, the presence of the polymer also accounts for the poor cyclability behavior. Fang et al. chose a different approach by depositing $\mathrm{RuO}_{2}$ on N-doped CNT [240], for which they measured considerably higher specific capacitances. The authors showed that the $\mathrm{RuO}_{2}$ particles were considerably better dispersed on N-doped CNTs than on pure CNTs, due to the presence of structural defects in $\mathrm{N}-\mathrm{CNT}$. Consequently, the hybrids with N-doped CNTs had an enhanced interface, which resulted in their better performance as a supercapacitor (Fig. 13).
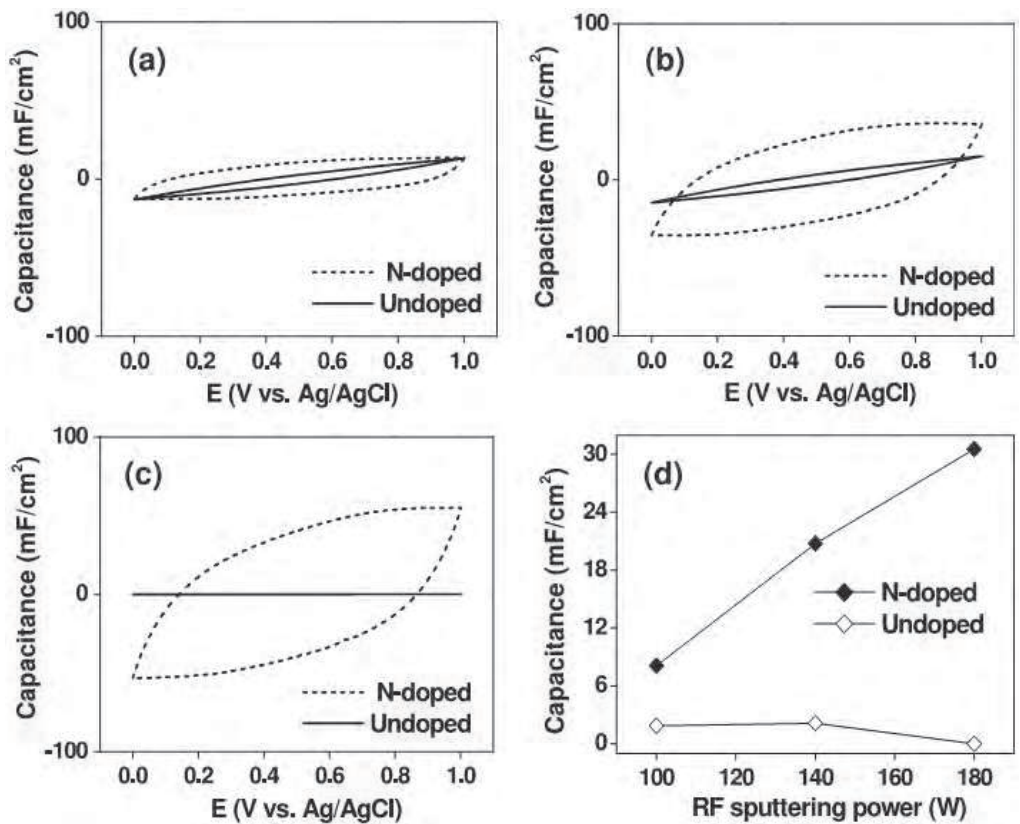

Fig. 13. Capacitance voltage diagrams of hybrids with $\mathrm{RuO}_{2}$ using undoped and nitrogendoped CNTs; (a) light (RF power $100 \mathrm{~W}$ ), (b) moderate (RF power $140 \mathrm{~W}$ ), and (c) heavy (RF power $180 \mathrm{~W}$ ) loading of $\mathrm{RuO}_{2}$. (d) Capacitance of hybrids as a function of RF sputtering power. In contrast to the undoped CNTs, the N-doped CNTs are coated completely with $\mathrm{RuO}_{2}$, resulting in a larger interfacial area and an improved capacitance. (Courtesy of A. L. M. Reddy et al. [240])

A good cyclability is crucial to a successful application as an anode material for lithium-ion batteries, as demonstrated by Chen et al. for CNT/SnOx hybrids [164]. Pure CNTs typically show good cycle stability, but also a large and irreversible capacity loss in the first cycle. The authors showed that well-dispersed SnOx on CNTs enhanced the electrochemical performance significantly as the capacity fade of the hybrid electrode was strongly reduced 
compared to unsupported SnOx or pure CNT. The authors attributed the improvement in performance to the enhanced conductivity and ductility of the hybrid. This is in line with Zheng et al., who observed a 5-fold increase in electronic conductivity and thus enhanced cycling rate and stability in $\mathrm{CNT} / \mathrm{CuO}$ hybrids compared to pure $\mathrm{CuO}$.

In summary, electrochemical devices have been among the first applications for which $\mathrm{CNT} /$ metal oxide hybrids were tested. In the long run, CNT hybrids are expected to strongly enhance the batteries' intrinsic capacities, stabilities, and lifetimes, as well as the charging/discharging characteristics. Furthermore, the substitution of part of the heavy oxide material (e.g., in car batteries) with the lightweight CNTs will significantly reduce the weight of the batteries.

\section{Conclusion and future directions}

As reviewed in the former publications, numerous synthetic methodologies have been developed for the preparation of CNTs and composites. In this chapter, besides the preparation of nanocomposites based on CNTs, we also focus on investigating the electrochemical applications CNT/metal oxide or hydroxide composites. There is a wealth of opportunities for nanoscale electrochemical devices based on carbon materials. Furthermore, when the electrode dimension approaches the double layer thickness, interesting and unusual kinetic and electrostatic effects occur. It is likely that carbon nanotubes electrodes will be key players in the investigation of such phenomena.

\section{Acknowledgments}

Financial support from Zhejiang Provincial Natural Science Foundation of China (Y4110304), Zhejiang Qianjiang Talent Project (2010R10025), the Educational Commission of Zhejiang Province of China (Z200909406) are gratefully acknowledged.

\section{References}

[1] J. Li, S. B. Tang, L. Lu, H. C. Zeng. J. Am. Chem. Soc. 2007, 129, 9401

[2] S. Iijima. Nature. 1991, 354, 56

[3] S. Iijima. Nature. 1993, 363, 603

[4] P. J. F. Harris. Carbon Nanotubes and Related Structures; Cambridge University Press: Cambridge, U.K., 2003.

[5] A. C. Dillon, M. Yudasaka, M. S. Dresselhaus. J. Nanosci. Nanotechnol. 2004, 407, 691

[6] P. Avouris. MRS Bull. 2004, 29, 403

[7] A. Jorio, G. Dresselhaus, M. S. Dresselhaus. Carbon Nanotubes: ad anced topics in sythesis, structure and properties; Springer: New York, 2007

[8] A. C. Dillon, K. M. Jones, T. A. Bekkedahl, C. H. Kiang, D. S. Bethune, M. J. Heben. Nature. 1997, 386, 377

[9] A. C. Dillon, A. H. Mahan, J. L. Alleman, M. J. Heben, P. A. Parilla, K. M. Jones. Thin Solid Films. 2003, 430, 292

[10] J. H. Lehman, C. Engtrakul, T. Gennett, A. C. Dillon. Appl. Opt. 2005, 44, 483

[11] J. H. Lehman, R. Deshpande, P. Rice, A. C. Dillon. IR Phys. 2006, 47, 246

[12] A. C. Dillon, M. J. Heben. Appl. Phys. A: Mater. Sci. Process. 2001, 72, 133 
[13] A. C. Dillon, A. H. Mahan, R. Deshpande, J. L. Alleman, J. L. Blackburn, P. A. Parillia, M. J. Heben, C. Engtrakul, K. E. H. Gilbert, K. M. Jones, R. To, S. H. Lee, J. H. Lehman. Thin Solid Films. 2006, 501, 216

[14] D. S. Bethune, C. H. Kiang, M. S. d. Vries, G. Gorman, R. Savoy, J. Vasquez, R. Beyers. Nature. 1993, 363, 605

[15] C. Journet, W. K. Maser, P. Bernier, A. Loiseau, M. Lamy de la Chapells, S. Lefrant, P. Deniard, R. Lee, J. E. Fischer. Nature. 1997, 388, 756

[16] S. Bandow. Private Communication.

[17] T. Guo, P. Nikolaev, A. Thess, D. T. Colbert, R. E. Smalley. Chem. Phys. Lett. 1995, 243, 49

[18] A. Thess, R. Lee, P. Nikolaev, H. Dai, P. Pitit, J. Robert, C. Xu, Y. H. Lee, S. G. Kim, A. G. Rinzler, D. T. Colbert, G. E. Scuseria, D. Tomanek, J. E. Fischer, R. E. Smalley. Science. 1996, 273, 483

[19] M. J. Heben, A. C. Dillon, K. E. H. Gilbert, P. A. Parilla, T. Gennett, J. L. Alleman, G. L. Hornyak, K. M. Jones. Hydrogen Mater. Vac. Syst. 2002, 671, 77

[20] A. C. Dillon, P. A. Parilla, J. L. Alleman, T. Gennett, K. M. Jones, M. J. Heben. Chem. Phys. Lett. 2005, 401, 522

[21] H. Kataura, Y. Maniwa, M. Abe, A. Fujiwara, T. Kodama, K. Kikuchi, H. Imahori, Y. Misaki, S. Suzuki, Y. Achiba. Appl. Phys. A: Mater. Sci. Process. 2002, 74, 349

[22] A. C. Dillon, T. Gennett, K. M. Jones, J. L. Alleman, P. A. Parilla, M. J. Heben. Adv. Mater. 1999, 11, 1354

[23] H. Dai, A. G. Rinzler, P. Nikolaev, A. Thess, D. T. Colbert, R. E. Smalley. Chem. Phys. Lett. 1996, 260, 471

[24] A. Peigney, C. Laurent, F. Dobigeon, A. J. Rousset. Mater. Res. 1997, 12, 613

[25] J. H. Hafner, M. J. Bronikowski, B. R. Azamian, P. Nikolev, A. G. Rinzler, D. T. Colbert, K. A. Smith, R. E. Smalley. Chem. Phys. Lett. 1998, 296, 195

[26] H. M. Cheng, F. Li, G. Su, H. Y. Pan, L. L. He, X. Sun, M. S. Dresselhaus. Appl. Phys. Lett. 1998, 72, 3282

[27] A. M. Cassell, J. A. Raymakers, J. Kong, H. J. Dai. Phys. Chem. B. 1999, 103, 6484

[28] J. -F. Colomer, C. Stephan, S. Lefrant, G. Van Tendeloo, I. Willems, Z. Konya, A. Fonseca, C. Laurent, J. B. Nagy. Chem. Phys. Lett. 2000, 317, 83

[29] M. Su, B. Zheng, J. Liu. Chem. Phys. Lett. 2000, 322, 321

[30] M. J. Bronikowski, P. A. Willis, D. T. Colbert, K. A. Smith, R. E. Smalley. J. Vac. Sci. Technol. A 2001, 19, 1800

[31] Q. Li, Y. Hao, C. Yan, Z. Jin, Z. Liu. J. Mater. Chem. 2002, 12, 1179

[32] G. L. Hornyak, L. Grigorian, A. C. Dillon, P. A. Parilla, K. M. Jones, M. J. Heben. J. Phys. Chem. B. 2002, 106, 2821

[33] L. M. Wagg, G. L. Hornyak, L. Grigorian, A. C. Dillon, K. M. Jones, J. Blackburn, P. A. Parilla, M. J. Heben. J. Phys. Chem. B. 2005, 109, 10435

[34] J. H. Hafner, C.-L. Cheung, T. H. Oosterkamp, C. M. Lieber. J. Phys. Chem. B. 2001, 105, 743

[35] A. H. Mahan, J. L. Alleman, M. J. Heben, P. A. Parilla, K. M. Jones, A. C. Dillon. Appl. Phys. Lett. 2002, 81, 4061

[36] I. W. Chiang, B. E. Brinson, A. Y. Huang, P. A. Willis, M. J. Bronikowski, J. L. Margrave, R. E. Smalley, R. H. Hauge. J. Phys. Chem. B. 2001, 105, 8297

[37] B. L. Liu, W. C. Ren, L. B. Gao, S. S. Li, S. F. Pei, C. Liu, C. B. Jiang, H. M. Cheng. J. Am. Chem. Soc. 2009, 131, 2082

[38] T. W. Ebbesen, P. M. Ajayan. Nature. 1992, 358, 220 
[39] A. C. Dillon, A. H. Mahan, P. A. Parilla, J. L. Alleman, M. J. Heben, K. M. Jones, K. E. H. Gilbert. Nano Lett. 2003, 3, 1425

[40] W. D. Wang, P. Serp, P. Kalck, C. G. Silva, J. L. Faria. Mater. Res. Bull. 2008, 43, 958

[41] B. P. Ribaya, J. Leung, P. Brown, M. Rahman, C. V. Nguyen. Nanotechnology. 2008, 19

[42] L. Bokobza. Polymer 2007, 48, 4907

[43] R. P. Raffaelle, B. J. Landi, J. D. Harris, S. G. Bailey, A. F. Hepp. Materials Science and Engineering B-Solid State Materials for Advanced Technology. 2005, 233

[44] Q. Ngo, D. Petranovic, S. Krishnan, A. M. Cassell, Q. Ye, J. Li, M. Meyyappan, C. Y. Yang. IEEE Trans. Nanotechnol. 2004, 3, 311

[45] K. P. Gong, M. N. Zhang, Y. M. Yan, L. Su, L. Q. Mao, Z. X. Xiong, Y. Chen. Anal. Chem. 2004, 76, 6500

[46] H. T. Gomes, P. V. Samant, P. Serp, P. Kalck, J. L. Figueiredo, J. L. Faria. Appl. Catal., B. 2004, 54, 175

[47] A. Lueking, R. T. Yang. J. Catal. 2002, 206, 165

[48] L. C. Qin. J. Mater. Sci. Lett. 1997, 16, 457

[49] Y.-Y. Fan, F. Li, H.-M. Cheng, G. Su, Y.-D. Yu, Z.-H. Shen. J. Mater. Res. 1998, 13, 2342

[50] R. Marangoni, P. Serp, R. Feurer, Y. Kihn, P. Kalck, C. Vahlas. Carbon. 2001, 39, 443

[51] R. Andrews, D. Jacques, A. M. Rao, F. Derbyshire, D. Qian, X. Fan, E. C. Dickey, J. Chen. Chem. Phys. Lett. 1999, 303, 467

[52] M. Endo, K. Takeuchi, S. Igarashi, K. Kobori, M. Shiraishi, H. W. Kroto. J. Phys. Chem. Sol. 1993, 54, 1841

[53] M. Jose-Yacaman, M. Miki-Yoshida, L. Rendon, J. G. Santiesteban. Appl. Phys. Lett. 1993, 62, 202

[54] V. Ivanov, J. B. Nagy, P. Lambin, A. Lucas, X. B. Zhang, X. F. Zhang, D. Bernaerts, G. Van Tendeloo, S. Amelinckx, J. Van Landuyt. Chem. Phys. Lett. 1994, 223, 329

[55] J. T. L. Thong, C. H. Oon, W. K. Eng, W. D. Zhang, L. M. Gan. Appl. Phys. Lett. 2001, 79, 2811

[56] D. S. Tang, S. S. Xie, Z. W. Pan, L. F. Sun, Z. Q. Liu, X. P. Zou, Y. B. Li, L. J. Ci, W. Liu, B. S. Zou, W. Y. Zhou. Chem. Phys. Lett. 2002, 356, 563

[57] C. J. Lee, D. W. Kim, T. J. Lee, Y. C. Choi, Y. S. Park, W. S. Kim, Y. H. Lee, W. B. Choi, N. S. Lee, J. M. Kim, Y. G. Choi, S. C. Yu. Appl. Phys. Lett. 1999, 75, 1721

[58] S. Xie, W. Li, Z. Pan, B. Chang, L. Sun. Mater. Sci. Eng. A. 2000, 286, 11

[59] Y. J. Li, Z. Sun, S. P. Lau, G. Y. Chen, B. K. Tay. Appl. Phys. Lett. 2001, 79, 1670

[60] L. C. Qin, D. Zhou, A. R. Krauss, D. M. Gruen. Appl. Phys. Lett. 1998, 72, 3437

[61] M. Chen, C.-M. Chen, C.-F. Chen. J. Mater. Sci. 2002, 37, 3561

[62] Y. C. Choi, D. J. Bae, Y. H. Lee, B. S. Lee, G.-S. Park, W. B. Choi, N. S. Lee, J. M. Kim. J. Vac. Sci. Technol. A. 2000, 18, 1864

[63] S. J. Chung, S. H. Lim, C. H. Lee, J. Jang. Diamond Relat. Mater. 2001, 10, 248

[64] G. W. Ho, A. T. S. Wee, J. Lin, W. C. Tiju. Thin Solid Films. 2001, 388, 73

[65] H. Wang, J. Lin, C. H. A. Huan, P. Dong, J. He, S. H. Tang, W. K. Eng, T. L. Thong. J. Appl. Surf. Sci. 2001, 181, 248

[66] Q. Zhang, S. F. Yoon, J. Ahn, B. Gan, Rusli, M.-B. Yu. J. Mater. Res. 2000, 15, 1749

[67] H. J. Yoon, H. S. Kang, J. S. Shin, K. J. Son, C. H. Lee, C. O. Kim, J. P. Hong, S. N. Cha, B. G. Song, J. M. Kim, N. S. Lee. Physica B. 2002, 323, 344

[68] Y. S. Woo, D. Y. Jeon, I. T. Han, N. S. Lee, J. E. Jung, j. M. Kim. Diamond Relat. Mater. 2002, 11, 59

[69] H. Lee, Y.-S. Kang, P. S. Lee, J.-Y. Lee. J. Alloys Compd. 2002, 330, 569

[70] C. Bower, O. Zhou, W. Zhu, D. J. Werder, S. Jin. Appl. Phys. Lett. 2000, 77, 2767

[71] K. H. Park, K. M. Lee, S. Choi, S. Lee, K. H. Koh. J. Vac. Sci. Technol. B. 2001, 19, 946 
[72] T. Ono, H. Miyashita, M. Esashi. Nanotechnology. 2002, 13, 62

[73] J.-h. Han, B.-S. Moon, W. S. Yang, J.-B. Yoo, C. Y. Park. Surf. Coat. Technol. 2000, 131, 93

[74] Z. F. Ren, Z. P. Huang, J. W. Xu, J. H. Wang, P. Bush, M. P. Siegal, P. N. Provincio. Science. 1998, 282, 1105

[75] C.-F. Chen, C.-L. Lin, C.-M. Jpn. Wang. J. Appl. Phys. 2002, 41, L67

[76] G. X. Du, Z. P. Zhu, L. D. Zhang, J. L. Song. Mater. Lett. 2010, 64, 1179

[77] C. N. R. Rao, C. A. K. Müller Achim, The Chemistry of Nanomaterials: Synthesis, Properties and Applications, JohnWiley, 2004

[78] G. G.Wildgoose, C. E. Banks, R. G. Compton. Small. 2006, 2, 182

[79] V. Georgakilas, D. Gournis, V. Tzitzios, L. Pasquato, D. M. Guldi, M. Prato. J. Mater. Chem. 2007, 17, 2679

[80] X. G. Hu, S. J. Dong. J. Mater. Chem. 2008, 18, 1279

[81] D. Vairavapandian, P. Vichchulada, M. D. Lay. Anal. Chim. Acta. 2008, 626, 119

[82] X. Peng, J. Chen, J. A. Misewich, S. S.Wong. Chem. Soc. Rev. 2009, 38, 1076

[83] I. W. Chiang, R. E. Smalley, J. L. Margrave, R. H. Hauge. J. Phys. Chem. B. 2001, 106, 1157

[84] T. Tohji, H. Takahashi, Y. Shinoda, N. Shimizu, B. Jeyadevan, I. Matsuoka, Y. Saito, A. Kasuya, T. Ohsuna, K. Hiraga, Y. Nishina, Nature. 1996, 383, 679

[85] E. E. Dujardin, A. Krishnan, M. M. J. Treacy. Adv. Mater. 1998, 10, 611

[86] H.Y. Xu, R. H. Hauge, R. E. Smalley, Nano Lett. 2005, 5, 163

[87] H. T. Fang, C. G. Liu, C. Liu, F. Li, M. Liu, H. M. Cheng. Chem. Mater. 2004, 16, 5744

[88] C. J. Murphy R., M. Cadek, B. McCarthy, M. Bent, A. Drury. J. Phys. Chem. B. 2002, 106, 3087

[89] K. Shen, S. Curran, H. F. Xu, S. Rogelj, Y. B. Jiang, J. Dewald, T. Pietrass. J. Phys. Chem. B. $2005,109,4455$

[90] A. G. Liu, H. Dai, J. H. Hafner, R. K. Bradley, P. J. Boul, A. Lu, T. Iverson, K. She-limov, C. B. Huffman, F. Rodriguez-Macias, Y. -S. Shon, T. R. Lee, D. T. Colbert, R. E. Smalley. Science. 1998, 280, 1253

[91] M. A. Chen, H. Hu, Y. Chen, A. M. Rao, P. C. Eklund, R. C. Haddon. Science. 1998, 282, 95

[92] W. Fu, Y. Lin, L. A. Riddle, D. L. Carroll, Y. -P. Sun. Nano Lett. 2001, 1, 439

[93] M. E. Kamaras, H. Hu, B. Zhao, R. C. Haddon. Science. 2003, 301, 1501

[94] C. A. Strano, M. L. Usrey, P. W. Barone, M. J. Allen, H. Shan, C. Kittrell, R. H. Hauge, J. M. Tour, R. E. Smalley, T. W. Dujardin, A. Ebbesen, M. Krishnan, M. J. Treacy. Science. 2003, 301, 1519

[95] A. Zheng, E. D. Semke, B. A. Diner, R. S. McLean, S. R. Lustig, R. E. Richardson, N. G. Tassi. Nat. Mater. 2003, 2, 338

[96] Y. Chen, D.Wang, H. Dai. J. Am. Chem. Soc. 2002, 123, 3838

[97] J. -O. Besteman, F. G. M. Wiertz, H. A. Heering, C. Dekker. Nano Lett. 2003, 3, 727

[98] M. S. Moore, E. H. Haroz, R. H. Hauge, R. E. Smalley, J. Schmidt, Y. Talmon. Nano Lett. 2003, 3, 1379

[99] A. Fukushima, Y. Ishimura, T. Yamamoto, T. Takigawa, N. Ishii, T. Aida. Science. 2003, 300, 2072

[100] H. C. J. Wang, Y. Li. ACS Nano. 2008, 2, 2540

[101] J. Y. Wang, Y. Li. J. Am. Chem. Soc. 2009, 131, 5364

[102] P. M. Ajayan, S. Lijima. Nature. 1993, 361, 333

[103] P. M. Ajayan, T. W. Ebbesen, T. Ichihashi, S. Iijima, K. Tanigaki, H. Hiura. Nature. 1993, 362, 522

[104] J. Sloan, J. Hammer, M. Zwiefka-Sibley, M. L. H. Green. Chem. Commun. 1998, 3, 347 
[105] C. Z. Loebick, M. Majewska, F. Ren, G. L. Haller, L. D. Pfefferle. J. Phys. Chem. C. 2010, 114,11092

[106] D. Jain, R. Wilhelm. Carbon. 2007, 45, 602

[107] M. C. Schnitzler, M. M. Oliveira, D. Ugarte, A. J. G. Zarbin. Chem. Phys. Lett. 2003, 381,541

[108] M. Monthioux, E. Flahaut, J. P. Cleuziou. J. Mater. Res. 2006, 21, 2774

[109] J. Chen, M. A. Hamon, H. Hu, Y. S. Chen, A. M. Rao, P. C. Ecklund, R. C. Haddon. Science. 1998, 282, 95

[110] J. M. Haremza, M. A. Hahn, T. D. Krauss, S. Chen, J. Calcines. Nano Lett. 2002, 2, 1253

[111] G.-X. Wang, B.-L. Zhang, Z.-L. Yu, M.-Z. Qu. Solid State Ionics. 2005, 176, 1169

[112] B. Liu, J. H. Chen, C. H. Xiao, K. Z. Cui, L. Yang, H. L. Pang, Y. F. Kuang. Energy Fuels. $2007,21,1365$

[113] A. Kongkanand, R. M. Dominguez, P. V. Kamat. Nano Lett. 2007, 7, 676

[114] T. Sainsbury, D. Fitzmaurice. Chem. Mater. 2004, 16, 3780

[115] D. Q. Yang, B. Hennequin, E. Sacher. Chem. Mater. 2006, 18, 5033

[116] D. M. Guldi, G. M. A. Rahman, N. Jux, N. Tagmatarchis, M. Prato. Angew. Chem. Int. Ed. 2004, 43, 5526

[117] R. J. Chen, Y. Zhang, D. Wang, H. Dai. J. Am. Chem. Soc. 2001, 123, 3838

[118] H. Murakami, T. Nomura, N. Nakashima. Chem. Phys. Lett. 2003, 378, 481

[119] A. Satake, Y. Miyajima, Y. Kobuke. Chem. Mater. 2005, 17, 716

[120] G. M. A. Rahman, D. M. Guldi, S. Campidelli, M. Prato. J. Mater. Chem. 2006, 16, 62

[121] X. Wang, Y. Liu, W. Qiu, D. Zhu. J. Mater. Chem. 2002, 12, 1636

[122] F. D'Souza, R. Chitta, A. S. D. Sandanayaka, N. K. Subbaiyan, L. D'Souza, Y. Araki, O. Ito. Chem.sEur. J. 2007, 13, 8277

[123] Y. Mu, H. Liang, J. Hu, L. Jiang, L. Wan. J. Phys. Chem. B. 2005, 109, 22212

[124] V. Georgakilas, V. Tzitzios, D. Gournis, D. Petridis. Chem. Mater. 2005, 17, 1613

[125] J. Zhou, X. Zhou, X. Sun, R. Lib, M. Murphy, Z. Ding, X. Sun, T.-K. Sham. Chem. Phys. Lett. 2007, 437, 229

[126] D. M. Guldi, H. Taieb, G. M. A. Rahman, N. Tagmatarchis, M. Prato. Adv. Mater. 2005, 17,871

[127] M. A. Correa-Duarte, L. M. Liz-Marza'n. J. Mater. Chem. 2006, 16, 22

[128] H. Chen, S. Donga. Talanta. 2006, 71, 1752

[129] J. W. Ostranger, A. A. Mamedov, N. A. Kotov. J. Am. Chem. Soc. 2001, 123, 1101

[130] K. Jiang, A. Eitan, L. S. Schadler, P. M. Ajayan, R. W. Siegel, N. Grobert, M. Mayne, M. Reyes-Reyes, H. Terrones, M. Terrones. Nano Lett. 2003, 3, 275

[131] M. A. Correa-Duarte, J. Perez-Juste, A. Sanchez-Iglesias, M. Giersig. Angew. Chem. Int. Ed. 2005, 44, 4375

[132] X. Hu, T. Wang, X. Qu, S. Dong. J. Phys. Chem. B. 2006, 110, 853

[133] J. Sun, L. Gao. J. Electroceram. 2006, 17, 91

[134] J. Sun, M. Iwasa, L. Gao, Q. Zhang. Carbon. 2004, 42, 895

[135] F. Stoffelbach, A. Aqil, C. Jerome, R. Jerome, C. Detrembleur. Chem. Commun. 2005, 4532

[136] D. J. Guo, H. L. Li. Electrochem. Commun. 2004, 6, 999

[137] T. M. Day, P. R. Unwin, N. R. Wilson, J. V. Macpherson. J. Am. Chem. Soc. 2005, 127, 10639

[138] D. J. Guo, H. L. Li. J. Electroanal. Chem. 2004, 573, 197

[139] Y. Xing. J. Phys. Chem. B. 2004, 108, 19255

[140] Y. Lin, X. Cui, C. Yen, C. M. Wai. J. Phys. Chem. B. 2005, 109, 14410 
[141] S. R. Sivakkumar, J. M. Ko, D. Y. Kim, B. C. Kim, G. G. Wallace. Electrochim. Acta. 2007, 52, 7377

[142] X. Xie, L. Gao. Carbon. 2007, 45, 2365

[143] X. P. Huang, C. X. Pan, X. T. Huang. Mater. Lett. 2007, 61, 934

[144] B. Huang, R. Huang, D. Jin, D. Ye. Catal. Today. 2007, 126, 279

[145] I. Moriguchi, R. Hidaka, H. Yamada, T. Kudo, H. Murakami, N. Nakashima. Adv. Mater. 2006, 18, 69

[146] J. Sun, L. Gao, M. Iwasa. Chem. Commun. 2004, 832

[147] O. Frank, M. Kalbac, L. Kavan, M. Zukalova, J. Prochazka, M. Klementova, L. Dunsch. Phys. Status Solidi. 2007, 244, 4040

[148] K.-X. He, Q.-F. Wu, X.-G. Zhang, X.-L. Wang. J. Electrochem. Soc. 2006, 153, A1568

[149] I.-H. Kim, J.-H. Kim, Y.-H. Lee, K.-B. Kim. J. Electrochem. Soc. 2005, 152, A2170

[150] J. D. Kim, B. S. Kang, T. W. Noh, J.-G. Yoon, S. I. Baik, Y.-W. Kim. J. Electrochem. Soc. 2005, 152, D23

[151] C. Wang, M. Waje, X. Wang, J. M. Tang, R. C. Haddon, Y. Yan. Nano Lett. 2004, 4, 345

[152] C. J. Brinker, G. W. Scherer. Sol Gel SciencesThe Physics and Chemistry of Sol Gel Processing; Academic Press: New York, 1990

[153] P. Vincent, A. Brioude, C. Journet, S. Rabaste, S. T. Purcell, J. L. Brusq, J. C. Plenet. J. Non-Cryst. Solids. 2002, 311, 130

[154] A. Jitianu, T. Cacciaguerra, R. Benoit, S. Delpeux, F. Beguin, S. Bonnamy. Carbon. 2004, 42,1147

[155] A. Jitianu, T. Cacciaguerra, M. H. Berger, R. Benoit, F. Beguin, S. Bonnamy. J. NonCryst. Solids. 2004, 34546, 596

[156] L. P. Zhao, L. Gao. Carbon. 2004, 42, 1858

[157] D. Eder, A. H. Windle. J. Mater. Chem. 2008, 18, 2036

[158] Y. Yu, J. C. Yu, J.-G. Yu, Y.-C. Kwok, Y.-K. Che, J.-C. Zhao, L. Ding, W.-K. Ge, P.-K. Wong. Appl. Catal., A. 2005, 289, 186

[159] H. Song, X. Qiu, F. Li, W. Zhu, L. Chen. Electrochem. Commun. 2007, 9, 1416

[160] W.-Q. Han, A. Zettl. Nano Lett. 2003, 3, 681

[161] J. Y. Bai, Z. D. Xu, Y. F. Zheng. Chem. Lett. 2006, 35, 96

[162] Y. Li, J. Ding, J. Chen, C. Xu, B. Wei, J. Liang, D. Wu. Mater. Res. Bull. 2002, 37, 313

[163] Y. X. Liang, Y. J. Chen, T. H. Wanga. Appl. Phys. Lett. 2004, 85, 666

[164] M. H. Chen, Z. C. Huang, G. T. Wu, G. M. Zhu, J. K. You, Z. G. Lin. Mater. Res. Bull. 2003, 38, 831

[165] B.-Y. Wei, M.-C. Hsu, P.-G. Su, H.-M. Lin, R.-J. Wu, H.-J. Lai. Sens. Actuators, B. 2004, 101,81

[166] W. D. Wang, P. Serp, P. Kalck, C. G. Silva, J. L. Faria. Mater. Res. Bull. 2008, 43, 958

[167] W. D. Wang, P. Serp, P. Kalck, J. L. Faria. J. Mol. Catal. A: Chem. 2005, 235, 194

[168] W. D. Wang, P. Serp, P. Kalck, J. L. Faria. Appl. Catal., B. 2005, 56, 305

[169] G. Arabale, D. Wagh, M. Kulkarni, I. S. Mulla, S. P. Vernekar, K. Vijayamohanan, A. M. Rao. Chem. Phys. Lett. 2003, 376, 207

[170] J. H. Park, J. M. Ko, O. O. Parka. J. Electrochem. Soc. 2003, 150, A864

[171] J. Y. Lee, K. Liang, K. H. Ana, Y. H. Lee. Synth. Met. 2005, 150, 153

[172] R.-J. Wu, J.-G. Wu, M.-R. Yu, T.-K T, C.-T. Yeh. Sens. Actuators, B. 2008, 131, 306

[173] L. Cao, F. Scheiba, C. Roth, F. Schweiger, C. Cremers, U. Stimming, H. Fuess, L. Chen, W. Zhu, X. Qiu. Angew. Chem. Int. Ed. 2006, 45, 5315

[174] D. Eder, A. H. Windle. Adv. Mater. 2008, 20, 1787

[175] K. Hernadi, E. Ljubovic, J. W. Seo, L. Forro. Acta Mater. 2003, 51, 1447

[176] F. Vietmeyer, B. Seger, P. V. Kamat. Adv. Mater. 2007, 19, 2935 
[177] L. Jiang, L. Gao. Mater. Chem. Phys. 2005, 91, 313

[178] M. Yoshimura, K. J. Byrappa. Mater. Sci. 2008, 43, 2085

[179] R. Menzel, A. M. Peiro', J. R. Durrant, M. S. P. Shaffer. Chem. Mater. 2006, 18, 6059

[180] K. Byrappa, A. S. Dayananda, C. P. Sajan, B. Basavalingu, M. B. Shayan, K. Soga, M. Yoshimura. J. Mater. Sci. 2008, 43, 2348

[181] Y. Lee, H. J. Song, H. S. Shin, H. J. Shin, H. C. Choi. Small. 2005, 1, 975

[182] Y. Huang, J. Lin, X. X. Ding, C. Tang, C. Z. Gu, S. R. Qi. Mater. Lett. 2007, 61, 697

[183] W. D. Zhang. Nanotechnology. 2006, 17, 1036

[184] Y. Yu, L. L. Ma, W. Y. Huang, J. L. Li, P. K. Wong, J. C. Yu. J. Solid State Chem. 2005, 178,1488

[185] Y. Yu, L. L. Ma, W. Y. Huang, F. P. Du, J. C. Yu, J. G. Yu, J. B. Wang, P. K. Wong. Carbon. 2005, 43, 670

[186] B. P. Jia, L. Gao, J. Sun. Carbon. 2007, 45, 1476

[187] L. Fu, Z. M. Liu, Y. Q. Liu, B. X. Han, J. Q. Wang, P. A. Hu, L. C. Cao, D. B. Zhu. Adv. Mater. 2004, 16, 350

[188] Z. Y. Sun, X. R. Zhang, B. X. Han, Y. Y. Wu, G. M. An, Z. M. Liu, S. D. Miao, Z. J. Miao. Carbon. 2007, 45, 2589

[189] X. Sun, Y. Chu, D. W. Wang, J. H. Du, B. Y. Zhang, F. P. Wang. Rare Metals. 2007, 26, 191

[190] Z. Sun, Z. Liu, B. Han, G. An. Mater. Lett. 2007, 61, 4565

[191] Z. Sun, H. Yuan, Z. Liu, B. Han, X. Zhang. Adv. Mater. 2005, 17, 2993

[192] Z. Sun, Z. Liu, B. Han, S. Miao, J. Du, Z. Miao. Carbon. 2006, 44, 888

[193] H. Kim, W. Sigmund. Appl. Phys. Lett. 2002, 81, 2085

[194] J. S. Ye, H. F. Cui, X. Liu, T. M. Lim, W. D. Zhang, F. S. Sheu. Small. 2005, 1, 560

[195] Y. W. Zhu, H. I. Elim, Y. L. Foo, T. Yu, Y. J. Liu, W. Ji, J. Y. Lee, Z. X. Shen, A. T. S. Wee, J. T. L. Thong, C. H. Sow. Adv. Mater. 2006, 18, 587

[196] F. Jin, Y. Liu, C. M. Day. Appl. Phys. Lett. 2007, 90, 143114

[197] W.-C. Fang, O. Chyan, C.-L. Sun, C.-T. Wu, C.-P. Chen, K.-H. Chen, L.-C. Chen, J.-H. Huang. Electrochem. Commun. 2007, 9, 239

[198] T. Ikuno, T. Yasuda, S. I. Honda, K. Oura, M. Katayama, J. G. Lee, H. J. Mori. Appl. Phys. 2005, 98, 114305

[199] T. Ikuno, M. Katayama, K. Kamada, S. Honda, J. G. Lee, H. Mori, K. Jpn. Oura. J. Appl. Phys. Lett. 2003, 42, L1356

[200] Q. Kuang, S. F. Li, Z. X. Xie, S. C. Lin, X. H. Zhang, S. Y. Xie, R. B. Huang, L. S. Zheng. Carbon. 2006, 44, 1166

[201] G. H. Deng, X. Xiao, J. H. Chen, X. B. Zeng, D. L. He, Y. F. Kuang. Carbon. 2005, 43, 1557

[202] Z. Fan, J. Chen, K. Cui, F. Sun, Y. Xu, Y. Kuang. Electrochim. Acta. 2007, 2007, 2959

[203] A. Chrissanthopoulos, S. Baskoutas, N. Bouropoulos, V. Dracopoulos, D. Tasis, S. N. Yannopoulos. Thin Solid Films. 2007, 515, 8524

[204] A. D. Lazareck, T.-F. Kuo, J. M. Xu, B. J. Taft, S. O. Kelley, S. G. Cloutier. Appl. Phys. Lett. 2006, 89, 103109

[205] A. D. Lazareck, S. G. Cloutier, T.-F. Kuo, B. J. Taft, S. O. Kelley, J. M. Xu. Nanotechnology. 2006, 17, 2661

[206] J. Liu, X. Li, L. Dai. Adv. Mater. 2006, 18, 1740

[207] Y. M. Ho, J. W. Liu, J. L. Qi, W. T. Zheng. J. Phys. D: Appl. Phys. 2008, 41, 665308

[208] A. Gomathi, S. R. C. Vivekchand, A. Govindaraj, C. N. R. Rao. Adv. Mater. 2005, 17, 2757 
[209] A. Javey, H. Kim, M. Brink, Q. Wang, A. Ural, J. Guo, P. Mcintyre, P. McEuen, M. Lundstrom, H. Dai. Nat. Mater. 2002, 1, 241

[210] N. Ren, A. G. Dong, W. B. Cai, Y. H. Zhang, W. L. Yang, S. J. Huo, Y. Chen, S. H. Xie, Z. Gao, Y. Tang. J. Mater. Chem. 2004, 14,3548

[211] J. Qiao, S. N. Tang, Y. N. Tiana, S. M. Shuang, C. Dong, M. M. F. Choi. Sens. Actuators B. $2009,138,402$

[212] G. Q. Mo, J. S. Ye, W. D. Zhang. Electrochimica Acta. 2009, 55, 511

[213] W. Ma, D. B. Tian. Bioelectrochemistry. 2010, 78, 106

[214] K. N. Zhu, H. Y. Qin, B. H. Liu, Z. P. Li. J. Power Sources. 2011, 196, 182

[215] T. Hirayama, T. Manako, H. Imai. e-J. Surf. Sci. Nanotech. 2008, 6, 237

[216] I. Jimenez, M. A. Centeno, R. Scotti, F. Morazzoni, A. Cornet, J. R. Morante. J. Electrochem. Soc. 2003, 150, H72

[217] B. Fru "hberger, M. Grunze, D. J. Dwyer. Sens. Actuators, B. 1996, 31, 167

[218] N. L. Wu, S. Y. Wang, I. A. Rusakova. Science. 1999, 285, 1375

[219] P. G. Collins, K. Bradley, M. Ishigami, A. Zettl. Science. 2000, 287, 1801

[220] N. Sinha, J. Z. Ma, J. T. W. Yeow. J. Nanosci. Nanotechnol. 2006, 6, 573

[221] J. Kong, N. R. Franklin, C. Zhou, M. G. Chapline, S. Peng, K. Cho, H. Dai. Science. 2000, 287, 622

[222] Z. Sun, X. Zhang, N. Na, Z. Liu, B. Han, G. An. J. Phys. Chem. B. 2006, 110, 13410

[223] N. Van Hieu, L. T. B. Thuy, N. D. Chien. Sens. Actuators, B. 2008, 129, 888

[224] J. Liu, Z. Guo, F. Meng, Y. Jia, J. Liu. J. Phys. Chem. C. 2008, 112, 6119

[225] Y. Chen, C. Zhu, T. Wang. Nanotechnology. 2006, 17, 3012

[226] L. C. Jiang, W. D. Zhang. Biosens. Bioelectron. 2010, 25, 1402

[227] Z. Liu, J. Wang, D. Xie, G. Chen. Small. 2008, 4, 462

[228] B. Fang, C. H. Zhang, W. Zhang, G. F. Wang, Electrochim. Acta. 2009, 55, 178

[229] B. E. Conway. J. Electrochem. Soc. 1991, 138, 1539

[230] C. Niu, E. K. Sichel, R. Hoch, D. Moy, H. Tennet. Appl. Phys. Lett. 1997, 70, 1480

[231] G. Lota, K. Lota, E. Frackowiak. Electrochem. Commun. 2007, 9, 1828

[232] W. Yi, S. G. Yu, W. T. Lee, I. T. Han, J. T. Jeong, Y. S. Woo, J. H. Lee, S. W. Jin, W. B. Choi, J. N. Heo, D. Jeon, J. M. Kim. J. Appl. Phys. 2001, 89, 4091

[233] K. W. Nam, K. H. Kim, E. S. Lee, W. S. Yoon, X. Q. Yang, K. B. Kim. J. Power Sources. $2008,182,642$

[234] V. Subramanian, H. W. Zhu, B. Q. Wei. Electrochem. Commun. 2006, 8, 827

[235] M. G. Deng, B. C. Yang, Z. A. Zhang, Y. D. Hu. J. Mater. Sci. 2005, 40, 1017

[236] H. Zhang, G. Cao, Z. Wang, Y. Yang, Z. Shi. Nano Lett. 2008, 8, 2664

[237] A. L. M. Reddy, M. M. Shaijumon, S. R. Gowda, P. M. Ajayan. Nano Lett. 2009, 9, 1002

[238] G.-M. Wu, A.-R. Wang, M.-X. Zhang, H.-Y. Yang, B. Zhou, J. J. Shen. Sol Gel Sci. Technol. 2008, 46, 79

[239] W.-C. Fang. J. Phys. Chem. C. 2008, 112, 11552

[240] W.-C. Fang, K.-H. Chen, L.-C. Chen. Nanotechnology. 2007, 18, 485716 


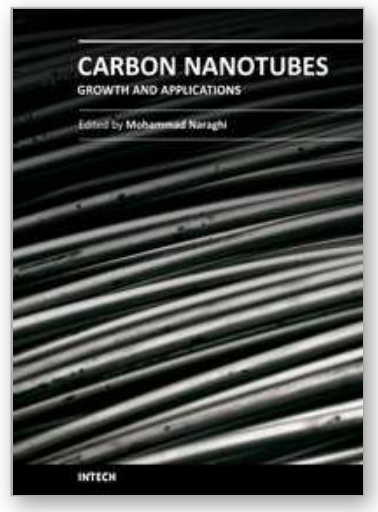

\section{Carbon Nanotubes - Growth and Applications}

Edited by Dr. Mohammad Naraghi

ISBN 978-953-307-566-2

Hard cover, 604 pages

Publisher InTech

Published online 09, August, 2011

Published in print edition August, 2011

Carbon Nanotubes are among the strongest, toughest, and most stiff materials found on earth. Moreover, they have remarkable electrical and thermal properties, which make them suitable for many applications including nanocomposites, electronics, and chemical detection devices. This book is the effort of many scientists and researchers all over the world to bring an anthology of recent developments in the field of nanotechnology and more specifically CNTs. In this book you will find:

- Recent developments in the growth of CNTs

- Methods to modify the surfaces of CNTs and decorate their surfaces for specific applications

- Applications of CNTs in biocomposites such as in orthopedic bone cement

- Application of CNTs as chemical sensors

- CNTs for fuelcells

- Health related issues when using CNTs

\section{How to reference}

In order to correctly reference this scholarly work, feel free to copy and paste the following:

Yong Hu and Changfa Guo (2011). Carbon Nanotubes and Carbon Nanotubes/Metal Oxide Heterostructures: Synthesis, Characterization and Electrochemical Property, Carbon Nanotubes - Growth and Applications, Dr. Mohammad Naraghi (Ed.), ISBN: 978-953-307-566-2, InTech, Available from:

http://www.intechopen.com/books/carbon-nanotubes-growth-and-applications/carbon-nanotubes-and-carbonnanotubes-metal-oxide-heterostructures-synthesis-characterization-and-el

\section{INTECH}

open science | open minds

\section{InTech Europe}

University Campus STeP Ri

Slavka Krautzeka 83/A

51000 Rijeka, Croatia

Phone: +385 (51) 770447

Fax: +385 (51) 686166

www.intechopen.com

\section{InTech China}

Unit 405, Office Block, Hotel Equatorial Shanghai

No.65, Yan An Road (West), Shanghai, 200040, China

中国上海市延安西路65号上海国际贵都大饭店办公楼 405 单元

Phone: +86-21-62489820

Fax: $+86-21-62489821$ 
(C) 2011 The Author(s). Licensee IntechOpen. This chapter is distributed under the terms of the Creative Commons Attribution-NonCommercialShareAlike-3.0 License, which permits use, distribution and reproduction for non-commercial purposes, provided the original is properly cited and derivative works building on this content are distributed under the same license. 